\title{
Analysis of the Spatial Spread of Sharka (Plum Pox Virus) in Apricot and Peach Orchards in Eastern Spain
}

\author{
T. R. GOTTWALD, Research Plant Pathologist, USDA, Agricultural Research Service, Orlando, FL 32803, L. \\ AVINENT, G. LLÁCER, A. HERMOSO DE MENDOZA, and M. CAMBRA, Research Plant Pathologists, Instituto \\ Valenciano de Investigaciones Agrarias (IVIA), Apartado Oficial, 46113 Moncada (Valencia), Spain
}

\begin{abstract}
Gottwald, T. R., Avinent, L., Llácer, G., Hermoso de Mendoza, A., and Cambra, M. 1995. Analysis of the spatial spread of sharka (plum pox virus) in apricot and peach orchards in eastern Spain. Plant Dis. 79:266-278.

Spatial patterns of sharka disease, caused by plum pox virus (PPV) and vectored by several species of aphid, were determined by double antibody sandwich-enzyme-linked immunosorbent assay using polyclonal antibodies in newly infected, mature apricot and peach orchards in eastern Spain. Among yearly assessments of plots examined for within- and across-row aggregation of adjacent sharka-diseased trees, only a few transects were found to have aggregation by ordinary runs analyses. Analyses, using beta-binomial index of dispersion $\left(\mathrm{I}_{B}\right)$ to determine if spatial aggregation was present in each plot for data partitioned into quadrats of different spatial dimension, demonstrated occasional aggregation and results were generally inconclusive. Significant $\left(\mathrm{I}_{\beta}\right)$ values, when present, were generally found associated with plots with higher disease incidence. No disease gradients were discernible for any of the plots and years. More rigorous spatial analyses were used to test for spatial relationships over longer distances. Twodimensional distance class analyses indicated a spatial dependency of PPV-infected stone-fruit trees over distance, a general scarcity of significant distance classes near the origin, and the presence of significant distance classes occasionally comprising small loose clusters at distances near the center or distal end of the proximity matrices especially during the initial stages of the epidemics. Geostatistical analysis confirmed the lack of significant associations among immediately adjacent trees and the trend for higher order spatial associations in semivariograms for distances corresponding to the center and distal ends of the proximity matrices. This trend in semivariance over distance was best described by linear or exponential increase models compared with transitional models commonly used in geostatistics. Correlation analysis indicated a significant conservation of orientation of localized systemic infections in scaffold branches over years. The spatial patterns of sharka suggest the lack of movement of PPV-viruliferous aphid vectors to immediately adjacent trees and their preferential movement to trees several tree spaces away.
\end{abstract}

Additional keywords: aphids, virus epidemiology

Sharka disease of stone fruits, caused by the plum pox potyvirus (PPV), was first detected in Bulgaria in 1915 and since has spread to most of the continent $(34,35,37)$. No case has yet been reported from outside the Euro-Mediterranean area.

The main woody hosts of PPV are the fruit-producing species of Prunus, including apricots (Prunus armeniaca

This work was funded by IV1A (Project 8133) and Commission of the European Communities, Contract N. 8001-CT91/0201. The first author visited the IVIA to analyze the data presented berein, supported by a feliowship from the Conselleria de Cultura, Educación i Ciència de la Generalitat Valenciana.

Mention of a trademark, warranty, proprietary product, or vendor does not constitute a guarantee by the U. S. Department of Agricuiture or Instituto Valenciano de Investigaciones Agrarias and does no imply its approval to the exclusion of other products or vendors that may also be suitable.

Accepted for publication 25 November 1994.

This article is in the public domain and not copyrightable. It may be freely reprinted with customary crediting of the source. The American Phytopathological Society. 1995.
Murcia, Valencia, Andalucía, and Cataluña $(4,24,34)$.

Primary introduction of the disease is by propagation and subsequent distribution of PPV-infected plant material. Secondary spread is rapid and accomplished by aphid vector. Aphis spiraecola Patch is thought to be the primary vector of PPV in Spain (23), although it occurs less frequently in Prunus orchards than A. gossypii Glover (1-3), which has not been demonstrated to vector PPV. Myzus persicae Sulzer is considered an even more efficient vector under laboratory conditions than $A$. spiraecola $(16,19,20,27)$, but its population leveis in Spanish orchards are extremely low $(1-3,15)$.

Various European strains of PPV differ in transmission rate by different aphid species, severity, and host range $(8,22,33)$. For example, the less common occurrence of aphids in apricot orchards, compared with other Prunus spp., may account for comparatively slower virus spread in apricot (33). The range of aphid spread in Prumus sp. nurseries is thought to be $100-120 \mathrm{~m}$ (8). Spatial studies of PPV spread are rare. In a rootstock trial of Italian prune, in which PPV-infected tree removal was practiced as a control strategy, new PPV-positive trees were commonly observed surrounding removed PPV-positive tree positions (14). In this study aphid transmission to surrounding trees was believed to have occurred prior to removal. In a study in apricot orchards in southern France, edge effects and gradients of up to $1 \mathrm{~km}$ in neighboring plots were observed (30). Both significant clustering and scattered trees with sharka symptoms were observed. Using a doublet-based analysis, greater than expected numbers of diseased trees occurred for 1,2 , and 3 tree distances from diseased trees. However, the authors questioned the accuracy of the study because they based their assessments on visual symptoms rather than serological detection, and thus did not consider latency of infection (30).

The study of viral and other grafttransmissible, fastidious pathogens of tree crops often dictates the use of serological or molecular probes for pathogen detection and confirmation. Data resulting from these analyses represents the presence or absence of the pathogen and, thus, are binary $(+/-)$. Several statistical procedures exist for the quantitative 
analysis of spatial patterns of disease at a single point in time. Ordinary runs analysis, which utilizes binary data, is the preferred method for unidirectional analysis to assess the presence or absence of aggregation of diseased individuals within columns and within rows in a population of diseased plants (26). Various indices of dispersion have been used to assess the degree of spatial randomness or aggregation of disease; however, these generally utilize quantitative data, which requires that the binary data be quadratized to enable the assignment of quantitative values to each spatial location $(6,29,39)$. Recently, the betabinomial discrete distribution has been demonstrated to be more appropriate than the negative binomial distribution to examine spatial patterns of disease incidence, i.e., binary data, for aggregation (17). Also, Gray's two-dimensional distance class analysis is based on binary data collected for a rectangular matrix to characterize the spatial relationships among diseased plants and is, therefore, well suited for the analysis of data from fastidious diseases of tree crops $(6,31,32)$.

Geostatistics is a type of spatial analysis based on regionalized variables, i.e., those depending on spatial position, and has been used in many fields of study including geography, geology, and soil science. Geostatistics has been recently adapted to entomology and plant pathology and, although the analysis is not specifically designed for binary data, it is tolerant of such data $(7,21,27,28$, $34,36,38)$. Geostatistical results are often presented as semivariograms, which represent the average of squared differences in values between pairs of samples separated by a given distance $(9,10,28$, 38,40 ). The intent of such an analysis is to detect spatial dependence by measuring the variation of regionalized variables among samples separated by the same distance $(28,38,40)$. Semivariograms can also be calculated for specific directions to test for anisotropy, a characteristic of regionalized variables that do not have the same properties in all directions. Anisotropy associated with plant diseases can be interpreted as indicative of directional spread (28, 38,40 ). By fitting theoretical transitional models to semivariance data, interpretations can be made concerning the structure of the spatial data and inferences drawn concerning the spatial relationships among plants over a range of distances, i.e., spatial lags. These geostatistical spatial models fall into two general categories. These are models with a sill or upper limit, which indicate a lack of spatial dependence at the farthest distances tested where semivariance no longer increases and becomes random, i.e., spherical, exponential, and Gaussian models; and models without a sill, i.e., linear, exponential, and power models $(36,40)$.
Systemic infection of PPV from new aphid transmissions is believed to require several months in mature orchard trees $(13,20)$. In peach, apricot, and plum orchards in Spain, sharka disease incidence can progress from very low to nearly $100 \%$ in $2-5$ yr (13). This prolonged period of titer increase combined with the rapid apparent infection rate makes temporal studies of sharka difficult and of questionable significance. The rapid spread of sharka by aphids appears to be the key to the observed high infection rates. Therefore, the purpose of this study was to examine the spatial dynamics of sharka in a typical commercial situation to better understand the spatial processes involved in aphid spread of PPV from trees in orchards with an initial low incidence during rapid periods of epidemic increase, using serological techniques.

\section{MATERIALS AND METHODS}

Field plots. The spread of PPV was followed in five plots in two orchards in the province of Valencia, Spain, from 1988 to 1991. Both orchards are on irrigated land, in an area where citrus coexists with stone fruits. In the first orchard, spread of PPV was assessed on trees in four plots all planted in 1965 on an $8 \times 8 \mathrm{~m}$ pattern with PPV-free materials and rows oriented along a north-south axis. The orchard was bordered to the east by a planting of PPV-infected Red Beaut plum that served as an inoculum source. Plot 1 comprised the western half of the orchard and consisted of 2.1 ha in 14 rows of 23 trees of Corbató apricot on apricot seedling rootstock; it was assessed yearly from 1988 to 1991. Plot 2 was bordered to the west by plot 1 and by the inoculum source to the east. Plot 2 consisted of 0.9 ha in 6 rows of 22 trees of Springerest peach on peach $X$ almond hybrid GF677 rootstock; it was assessed yearly from 1989 to 1991 . Plots 3a and 3b were also bordered to the west by plot 1 and by the inoculum source to the east. Plots $3 \mathrm{a}$ and $3 \mathrm{~b}$ consisted of 0.5 ha each with 7 rows of 12 trees and 7 rows of 11 trees,

Table 1. Ordinary runs analysis of the aggregation of sharka disease in stone-fruit orchards in the Valencia province of eastern Spain

\begin{tabular}{llllll}
\hline & Row & \multicolumn{3}{c}{ Year } \\
Plot & $\begin{array}{c}\text { Noction } \\
\text { direction }\end{array}$ & 1988 & 1989 & 1990 & 1991 \\
\hline 1 Corbató apricot & Within & $2 / 14$ & $1 / 14$ & $0 / 14$ & $0 / 14$ \\
& Across & $0 / 23$ & $0 / 23$ & $0 / 23$ & $2 / 23$ \\
2 Springcrest peach & Within & NA & $2 / 6$ & $1 / 6$ & $1 / 6$ \\
& Across & NA & $0 / 22$ & $0 / 22$ & $0 / 22$ \\
3a Blanco apricot & Within & $1 / 7$ & $1 / 7$ & NA & NA \\
& Across & $0 / 12$ & $0 / 12$ & NA & NA \\
3b Canino apricot & Within & $0 / 7$ & $1 / 7$ & NA & NA \\
& Across & $0 / 11$ & $1 / 11$ & NA & NA \\
4 Starcrest peach & Within & NA & NA & 0/11 & $0 / 11$ \\
& Across & NA & NA & I/17 & $1 / 17$ \\
\hline
\end{tabular}

${ }^{2}$ Values are number of rows in which disease is aggregated/total number of rows.

${ }^{b}$ No applicable comparison possible for this year. respectively, first established in 1965 as Corbató apricot on apricot seedling rootstock, then topworked in 1977 to Blanco (Plot 3a) and Canino (Plot 3b) apricot; they were assessed in 1988 and 1989. In the second orchard, a single planting, plot 4 , consisted of 0.5 ha in 11 rows of 24 trees of Starcrest peach on a hybrid peach $X$ almond rootstock (GF-677) and was planted in 1986 on a $4 \times 5 \mathrm{~m}$ grid. This orchard was bordered to the east by a single row of 14 Canino apricot, 13 of which were PPV-infected; it was assessed in 1990 and 1991.

Disease assessment. Plots were assessed each year preharvest for both fruit and foliar symptoms. The incidence $(+/-)$ of PPV in suspect trees was confirmed by double antibody sandwich-enzymelinked immunosorbent assay (DASELISA) technique using polyclonal antibodies described previously $(5,21)$. For plots $1,3 \mathrm{a}$, and $3 \mathrm{~b}$, in addition to disease incidence of trees, each tree was divided in four quadrants and individual branches within each quadrant were assessed visually for fruit and foliar symptoms. Quadrants were given a ranking of 0 to 4 based on the percentage of branches within each quadrant with symptoms (i.e., $0=0 \%, 1=1-25 \%, 2=25-50 \%$, $3=51-75 \%$, and $4=76-100 \%$ of branches in the quadrant with symptoms). Thus, individual trees had possible ranges of the sum of individual rankings of 0 to 16 .

Spatial analysis. Preliminary analyses were used to examine aggregation of adjacent trees. More rigorous analyses, aimed at examining more complex spatial relationships over longer distances, were then used. Ordinary runs analysis was performed on each data set to determine if aggregation existed between adjacent trees within- and/or across-rows (26). An aggregate of diseased trees was assumed for a particular row if the observed number of runs was less that the expected at $P=0.05$. To examine the data for the presence of aggregation in different spatial dimensions, the disease incidence data from each plot were partitioned into $2 \times 2,2 \times 3,3 \times 2,3 \times 3,4 \times 4$, and $6 \times 6$ tree 
quadrats, depending on the dimension of each plot. The index of dispersion $\left(\mathrm{l}_{\beta}\right)$, associated with the beta-binomial distribution, was used to test for the presence of aggregation at each tree-quadrat size (25).

Because the serological confirmations of disease resulted in simple binary data for each tree, (i.e., + or - PPV), twodimensional distance class analysis was used to examine the spatial patterns of diseased and healthy plants by the 2DCLASS computer program for personal computers (32). The observed standardized count frequency (SCF) for each $[X, Y]$ distance class was compared with expected SCFs, estimated by 400 computer simulations using a pseudorandom function and an equal number of diseased trees randomly distributed to generate test lattices of the same dimension. Two-dimensional distance class proximity patterns were interpreted as random if the number of significant SCFs $<5 \%$; aggregated if $5 \% \leq$ number of significant SCFs $\leq 80 \%$; and uniform if the number of significant SCFs $>80 \%$ of the total distance classes. Core clusters were interpreted as groupings of significantly greater than expected $[X, Y]$ distance classes that formed a discrete and contiguous group with the origin, i.e., distance class $[0,0](28,29)$. The data set was interpreted as having significant edge effects if $>10 \%$ of the $[X, Y]$ dis- tances classes in the distal (outermost) row and column of the proximity pattern had significantly greater than expected SCF values $(31,32)$. Cluster shape was defined as the shape of contiguous and adjacent $[X, Y]$ distance classes with significantly greater than expected SCF values that were noncontiguous with the core cluster. Cluster shapes were segregated into four categories: within-row = a linear pattern in the row axis; withincolumn = a linear pattern in the column axis; square/rectangular $=$ forming a square or rectangular pattern, and, amorphous $=$ patterns not fitting the other three definitions. Proximity patterns were prepared from the twodimensional distance class analysis output to visualize the results.

Geostatistical analysis was used to further examine and interpret twodimensional distance class proximity patterns by plotting the semivariance divided by the sample variance (to provide a common scale for comparison of standardized semivariograms among plots) vs. distance in meters $(27,38)$. Geostatistical analysis was performed using GEOPAK geostatistical software (Version 1.0e, USDA-ARS, Pesticides and Water Quality Research Unit, University of California, Riverside) for $0^{\circ}$ (omnidirectional with an angle of inclusion of $180^{\circ}$ ), and 45,90 , and $135^{\circ}$ relative to the rows in each plot with an angle of inclusion of $90^{\circ}$. Linear and exponential growth models were fit to semivariance vs. distance data by linear regression analysis via the SAS PROC REG subroutine. Linear, exponential, spherical, power, and Gaussian transitional models, most commonly used in geostatistics analyses, were fit to the semivariance [gamma $\gamma(h) / \mathrm{s}^{2}$, where $\gamma(h)$ is the semivariance and $\mathrm{s}^{2}$ is the sample variance] vs. distance data by means of nonlinear regression analysis performed via a GEOPAK model fitting subroutine. The model with the highest $r^{2}$ of correlation between observed and predicted values was considered the most descriptive of the spatial structure of semivariance to distance (36). For transitional models, the most appropriate model was used to estimate three interactive structures of the semivariogram, the localized discontinuity, the sill, and the range of spatial dependence. The localized discontinuity (nugget or $y$-intercept) is the measure of random variation and measurement of error. It can be interpreted as an estimate of the degree of aggregation. For instance, nugget values of 0.1 and 0.8 indicate very high and very low degrees of aggregation, respectively (10). The sill is the point along the $y$-axis at which the semivariance no longer increases, i.e., an asymptote of semivariance. The range of spatial dependence (RSD or range) is the distance

Table 2. Index of dispersion $\left(1_{\beta}\right)$ for the incidence of sharka caused by plum pox potyvirus (PPV) in stone-fruit orchards in the Valencia province of eastern Spain"

\begin{tabular}{|c|c|c|c|c|c|c|c|c|}
\hline \multirow[b]{2}{*}{ Plot } & \multirow[b]{2}{*}{ Year } & \multirow{2}{*}{$\begin{array}{c}\text { Sharka } \\
\text { incidence }\end{array}$} & \multicolumn{6}{|c|}{ Quadrat size } \\
\hline & & & $2 \times 2$ & $3 \times 2$ & $2 \times 3$ & $3 \times 3$ & $4 \times 4$ & $6 \times 6$ \\
\hline \multirow[t]{8}{*}{1 Corbató apricot } & 1988 & 0.05 & 0.87 & 0.99 & 1.07 & 0.91 & 1.34 & 1.04 \\
\hline & & & 0.787 & 0.481 & 0.340 & 0.598 & 0.154 & 0.390 \\
\hline & 1989 & 0.15 & 1.10 & 0.90 & 0.95 & 0.890 & 1.54 & 0.79 \\
\hline & & & 0.262 & 0.659 & 0.580 & 0.690 & 0.071 & 0.558 \\
\hline & 1990 & 0.52 & 1.42 & 1.63 & 1.61 & 1.90 & 3.08 & 4.55 \\
\hline & & & 0.009 & 0.005 & 0.005 & 0.003 & 0.000 & 0.000 \\
\hline & 1991 & 0.82 & 1.28 & 1.35 & 1.34 & 1.29 & 1.88 & 2.73 \\
\hline & & & 0.049 & 0.064 & 0.059 & 0.146 & 0.015 & 0.118 \\
\hline \multirow[t]{6}{*}{2 Springcrest peach } & 1989 & 0.34 & 2.86 & 2.75 & 3.96 & 3.93 & $\mathbf{N}^{c}$ & $\mathrm{~N}$ \\
\hline & & & 0.000 & 0.000 & 0.000 & 0.000 & & \\
\hline & 1990 & 0.23 & 2.86 & 3.08 & 3.51 & 3.76 & $\mathrm{~N}$ & $\mathrm{~N}$ \\
\hline & & & 0.000 & 0.000 & 0.000 & 0.000 & & \\
\hline & 1991 & 0.50 & 1.56 & 1.33 & 1.62 & 1.40 & $\mathrm{~N}$ & $\mathbf{N}$ \\
\hline & & & 0.022 & 0.140 & 0.039 & 0.150 & & \\
\hline \multirow[t]{4}{*}{ 3a Blanco apricot } & 1988 & 0.09 & 2.19 & 3.50 & 2.09 & 3.41 & $\mathrm{~N}$ & $\mathbf{N}$ \\
\hline & & & 0.003 & 0.000 & 0.018 & 0.001 & & \\
\hline & 1989 & 0.34 & 1.89 & 1.93 & 1.34 & 1.83 & $\mathrm{~N}$ & $\mathbf{N}$ \\
\hline & & & 0.015 & 0.032 & 0.196 & 0.076 & & \\
\hline \multirow[t]{4}{*}{ 3b Canino apricot } & 1988 & 0.39 & 1.83 & 1.56 & 1.73 & 1.64 & $\mathrm{~N}$ & $\mathrm{~N}$ \\
\hline & & & 0.029 & 0.120 & 0.087 & 0.145 & & \\
\hline & 1989 & 0.95 & 0.89 & 0.90 & 0.84 & 1.35 & $\mathrm{~N}$ & $\mathrm{~N}$ \\
\hline & & & 0.574 & 0.526 & 0.564 & 0.240 & & \\
\hline \multirow[t]{3}{*}{4 Starcrest peach } & 1990 & 0.13 & 1.28 & $\mathrm{~N}$ & $\mathbf{N}$ & 0.99 & 1.37 & $\mathrm{~N}$ \\
\hline & & & 0.116 & & & 0.541 & 0.182 & \\
\hline & 1991 & 0.17 & $\begin{array}{l}1.04 \\
0.405\end{array}$ & $\mathbf{N}$ & $\mathrm{N}$ & $\begin{array}{l}1.21 \\
0.261\end{array}$ & $\begin{array}{l}1.69 \\
0.069\end{array}$ & $\mathrm{~N}$ \\
\hline
\end{tabular}

"Index of dispersion $\left(\mathbf{I}_{\beta}\right)$ and associated probability $(P)$ values for the indicated quadrat sizes by year for Prumus plots in eastern Spain infected with plum pox virus. Values presented for each assessment date are $I_{\beta}(=$ observed variance $/$ binomial variance $)$ and $P(=$ significance probability). $P$ values were calculated by comparison of $\mathrm{df} \times \mathrm{I}_{\beta}$ with the chi-squared distribution. Values of $\mathrm{I}_{\beta}$ not significantly different from 1 ( 0.95 $>P>0.05)$ indicate that the pattern of diseased trees is indistinguishable from random. A large $(>1) I_{\beta}$ and a small $P(<=0.05)$ suggest rejection of $H_{0}:$ random pattern, in favor of $H_{1}$ : aggregated pattern of diseased trees.

'Incidence of diseased trees was determined by polyclonal enzyme-linked immunosorbent assay for PPV.

'No assessment data available for that year or too few data points were available to allow calculation. 

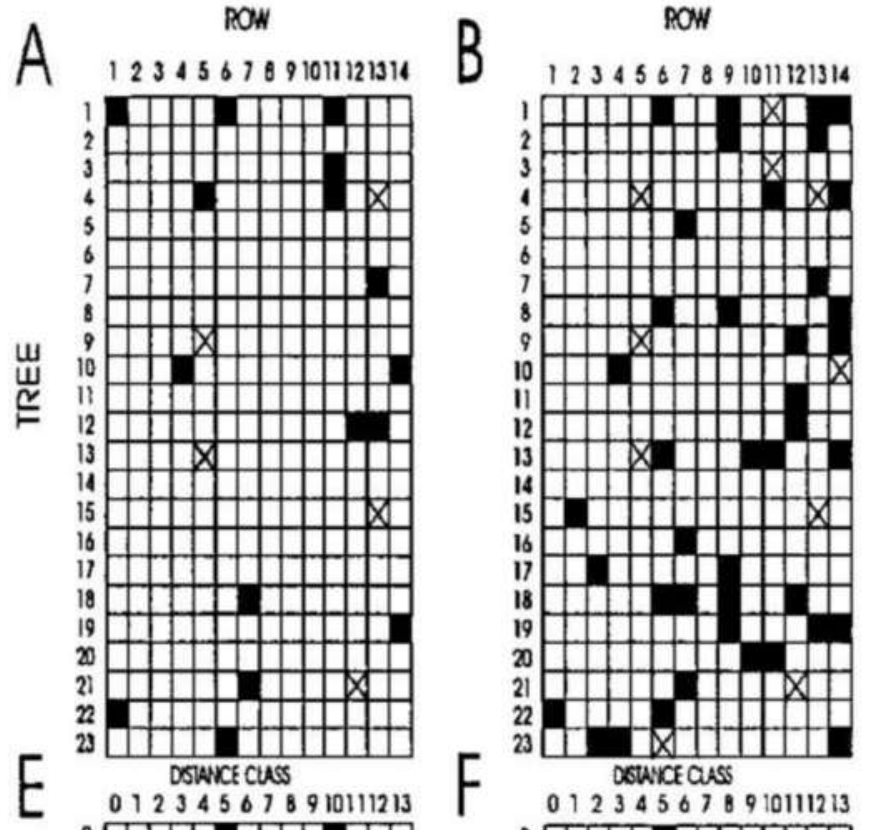

F
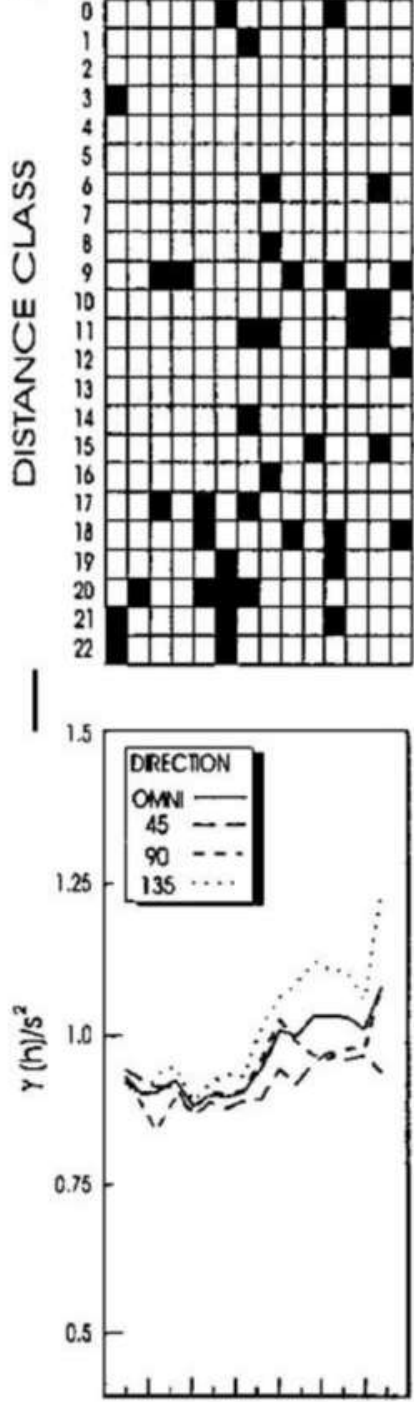

$\begin{array}{lllllllllll}0 & 20 & \omega 0 & 00 & 80 & 100120140\end{array}$

LAG DISTANCE (M)

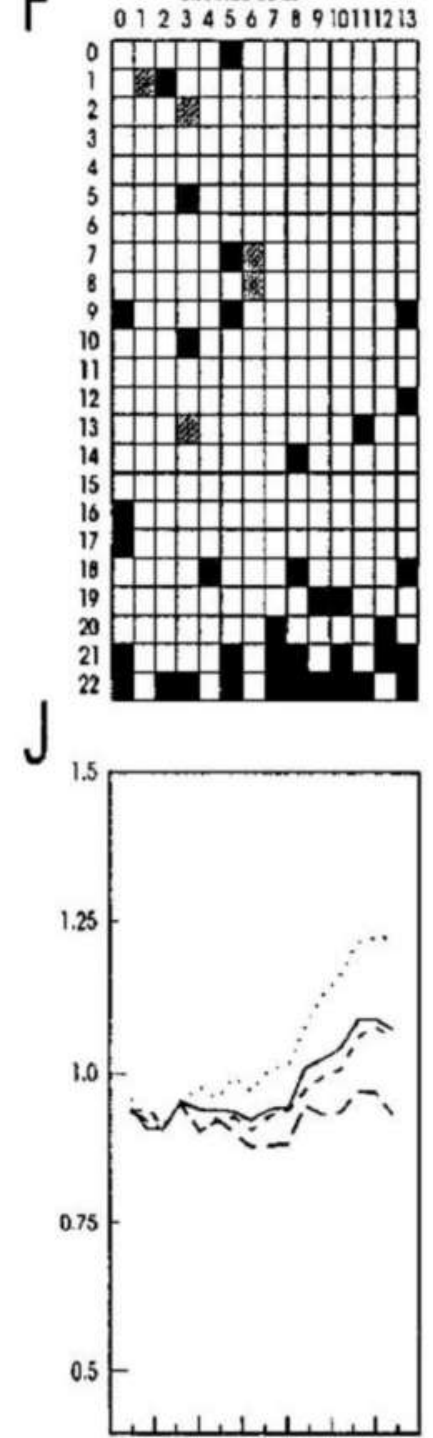

$\begin{array}{lllllllll}0 & 20 & 40 & 00 & 30 & 100 & 120140\end{array}$

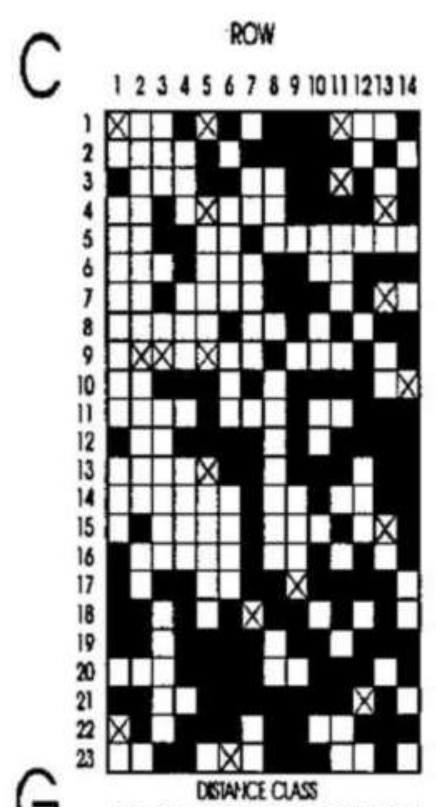

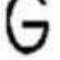

K

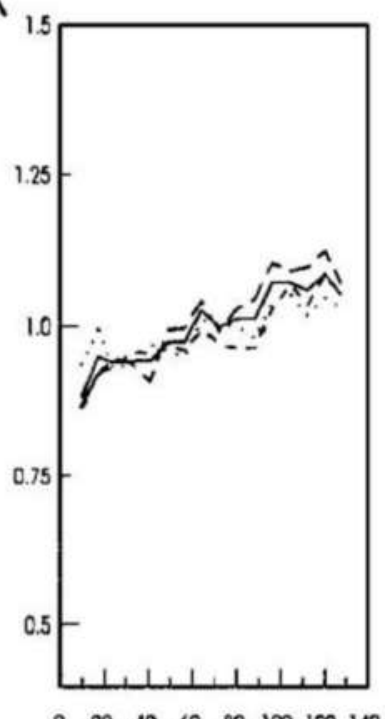

LAG DISTANCE (M)

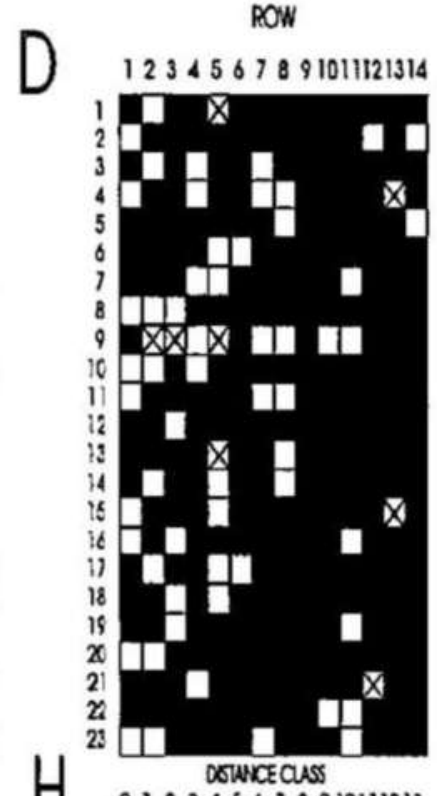

012345678910111213

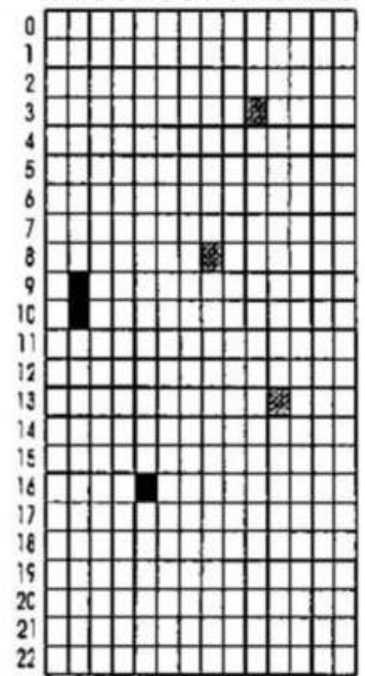

L

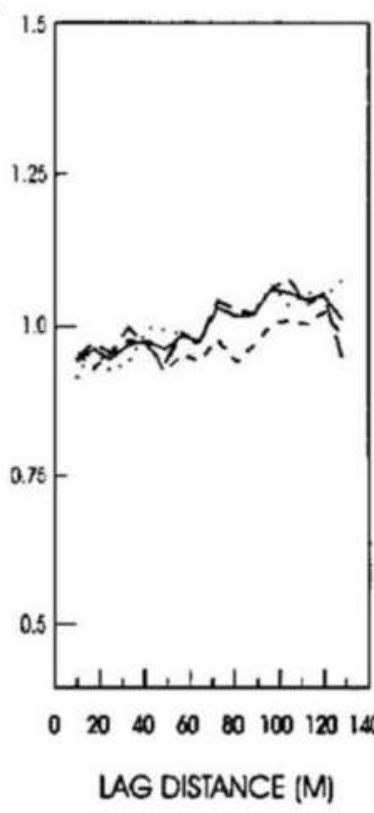

Fig. 1. Spatial pattern with associated two-dimensional distance class and geostatistical analyses by year of sharka disease of a Corbató apricot orchard (plot 1) in eastern Spain. (A-D) Spatial patterns were determined by double antibody sandwich-enzyme-linked immunosorbent assay using polyclonal antisera for plum pox potyvirus (PPV). Black squares, white squares, and squares with an 'X' indicate position of PPV positive, healthy and missing trees, respectively. (E-H) Proximity pattern matrices from two-dimensional distance class analyses. Black, gray and white squares indicate $[X, Y]$ distance classes with standardized count frequencies greater than expected, less than expected, and as expected, respectively $(P<0.05)$. (J-L) Nonoriented (solid line) and oriented (broken lines) semivariograms of sharka disease spread measured at onetree intervals. 


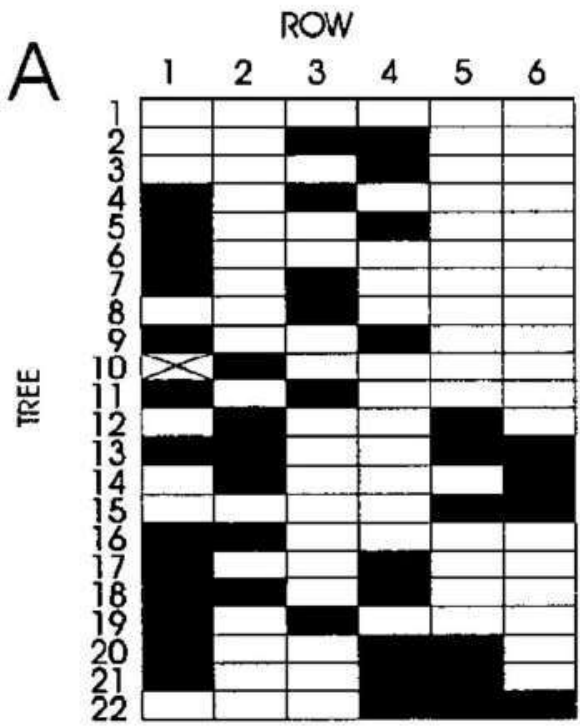

DISTANCE CLASS
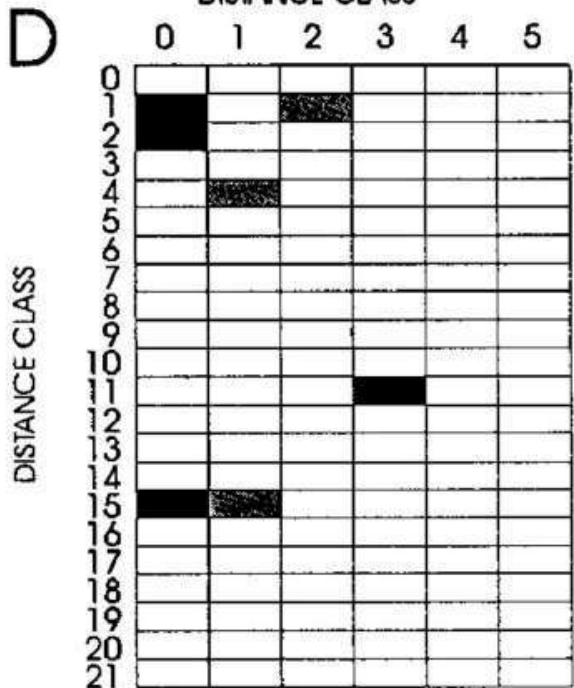

G

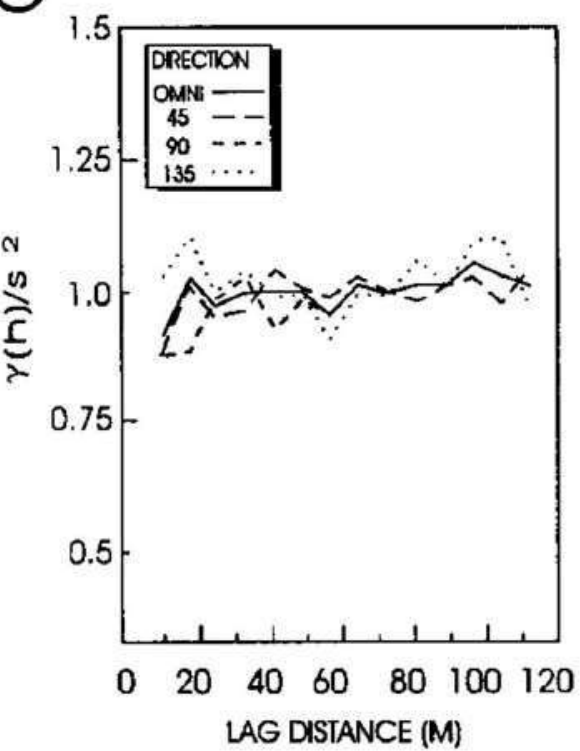

B

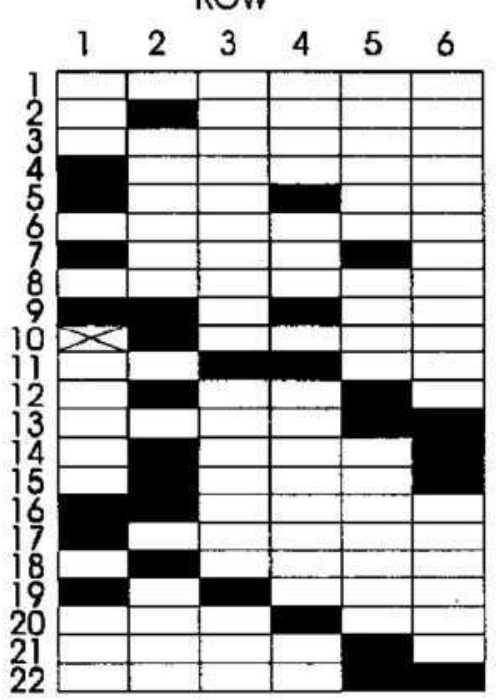

DISTANCE CLASS

E

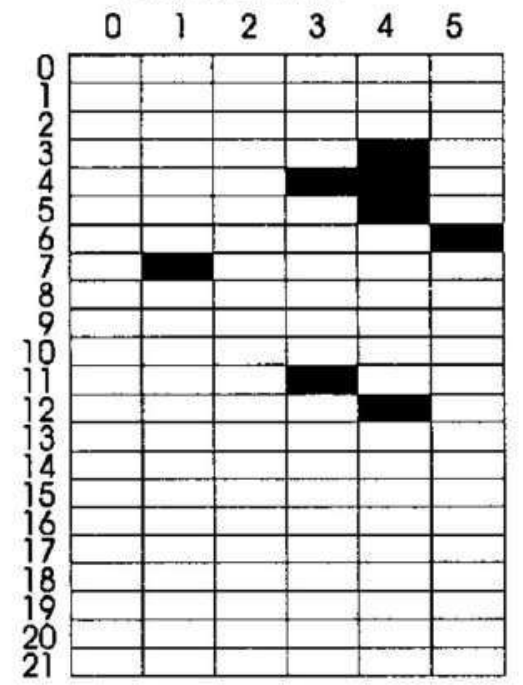

$\mathrm{H}$

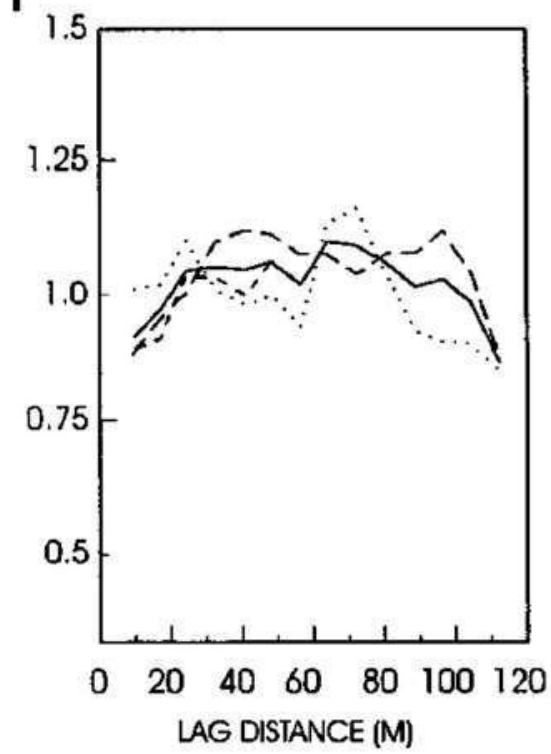

ROW

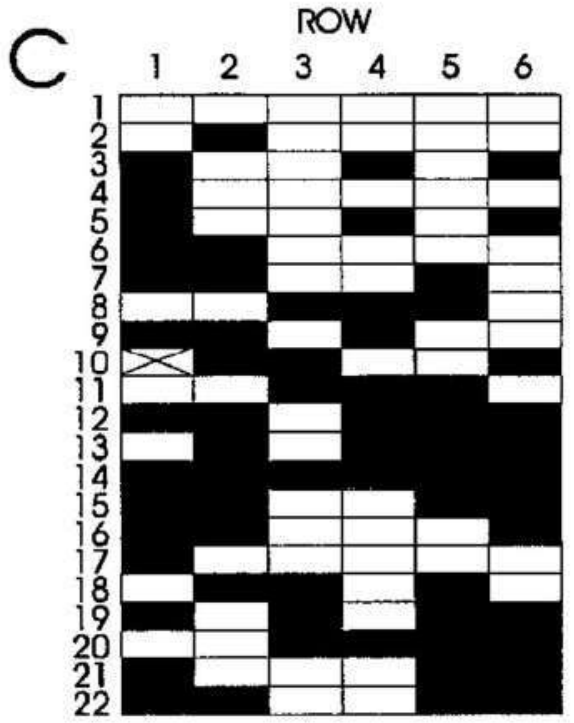

DISTANCE CLASS

$E$
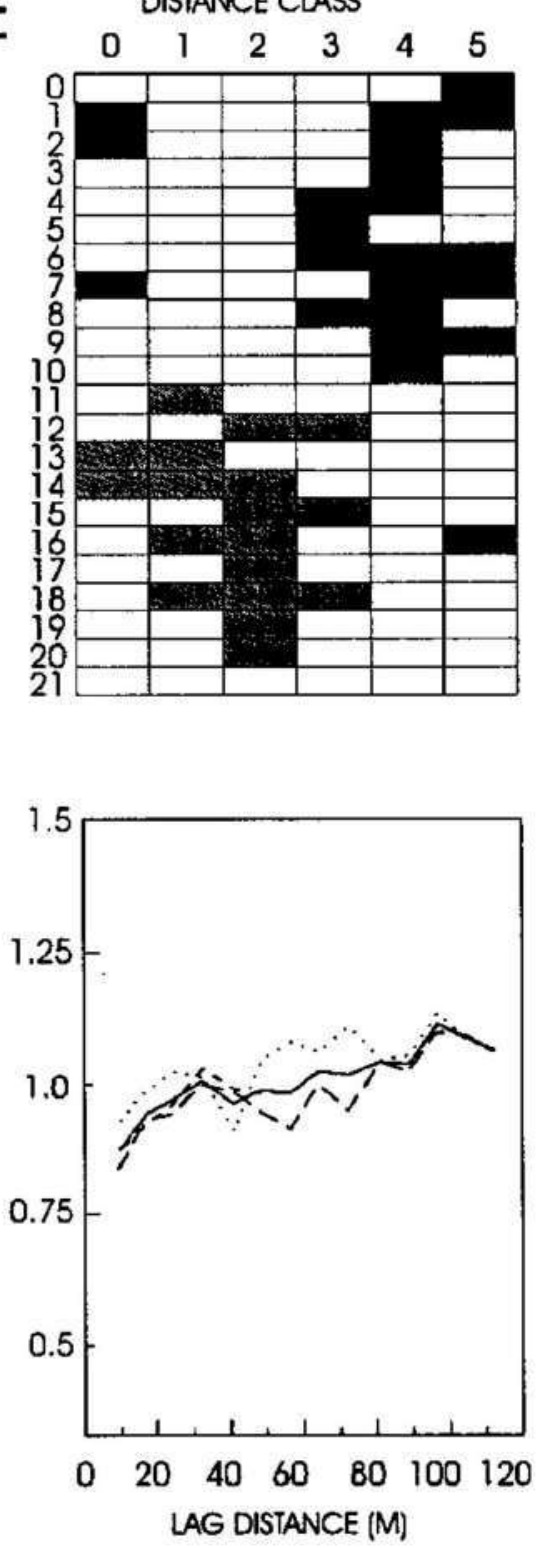

Fig. 2. Spatial pattern with associated two-dimensional distance class and geostatistical analyses by year of sharka disease of a Springcrest peach orchard (plot 2) in eastern Spain. (A-C) Spatial patterns were determined by double antibody sandwich-enzyme-linked immunosorbent assay using polyclonal antisera for plum pox potyvirus (PPV). Black squares, white squares, and squares with an ' $\mathrm{X}$ ' indicate position of PPV-positive, healthy, and missing trees, respectively. (D-F) Proximity pattern matrices from two-dimensional distance class analyses. Black, gray and white squares indicate $[X, Y]$ distance classes with standardized count frequencies greater than expected, less than expected, and as expected, respectively $(P<0.05)$. (G-I) Nonoriented (solid line) and oriented (broken lines) semivariograms of sharka disease spread measured at one-tree intervals. 
along the $x$-axis from the origin to the point at which the sill is attained. The two-dimensional spatial structure is considered anisotropic when directional semivariograms diverge from one another over distance (36).

PPV infections are thought to be locally systemic, i.e., causing sectoring of infections limited to one branch, side, or portion of the vascular system of a tree. To determine if symptoms were expressed preferentially on one side (orientation) of the tree and to examine if the orientation of infected branches was conserved from year to year, quadrant (orientation) ratings for each tree that reflected incidence of PPV-positive branches for plots $1,3 \mathrm{a}$, and $3 \mathrm{~b}$ were correlated with the ratings from the previous year via the SAS PROC CORR subroutine with the SPEARMAN option for rank correlation.

\section{RESULTS}

Disease incidence ranged over time from $0.05-0.82,0.34-0.50,0.09-0.34$, $0.39-0.95$, and $0.13-0.17$, for plots 1,2 , $3 \mathrm{a}, 3 \mathrm{~b}$, and 4 , respectively. In general, ordinary runs indicated weak or no within- or across-row aggregation of PPV-positive trees during any year tested (Table 1). Considering all plots, the small number of transects with aggregation was interpreted as indicative of a lack of aggregation of immediately adjacent, PPV-positive trees.

For plot 2, Springcrest peach, and plot $3 \mathrm{a}$, Blanco apricot, the beta-binomial index of dispersion $\left(\mathrm{I}_{\beta}\right)$ values indicated some aggregation for all quadrat sizes tested; however, these values eroded in magnitude to only slight indications of aggregation as disease incidence increased (Table 2). There was also an indication of aggregation for all quadrat sizes tested for plot 1, Springcrest peach, during 1990 , but $I_{\beta}$ eroded in magnitude by 1991 , when disease incidence exceeded 0.5 . For all other plot and year combinations and all quadrat sizes tested, the magnitude of $I_{\beta}$ values was near 1.0 , indicating no departure from randomness of sharka diseased trees.

With the exception of the Springerest peach assessment for 1990, ELISAconfirmed sharka disease incidence increased in all plots over time. No clearly definable disease gradients were observed in any of the plots. Twodimensional distance class analyses resulted in distance classes with significantly greater than expected SCF values in each plot for each year (Figs. 1-5). The number of distance classes with significantly greater than expected SCF values ranged from 1 to $16 \%$ and tended to increase over time as disease incidence increased (Table 3), with the exception of plot 1 , in which the number of significant distance classes decreased when disease incidence exceeded 0.8 , and plot 4 (Figs. $1 \mathrm{H}$ and 4D). When disease inci-
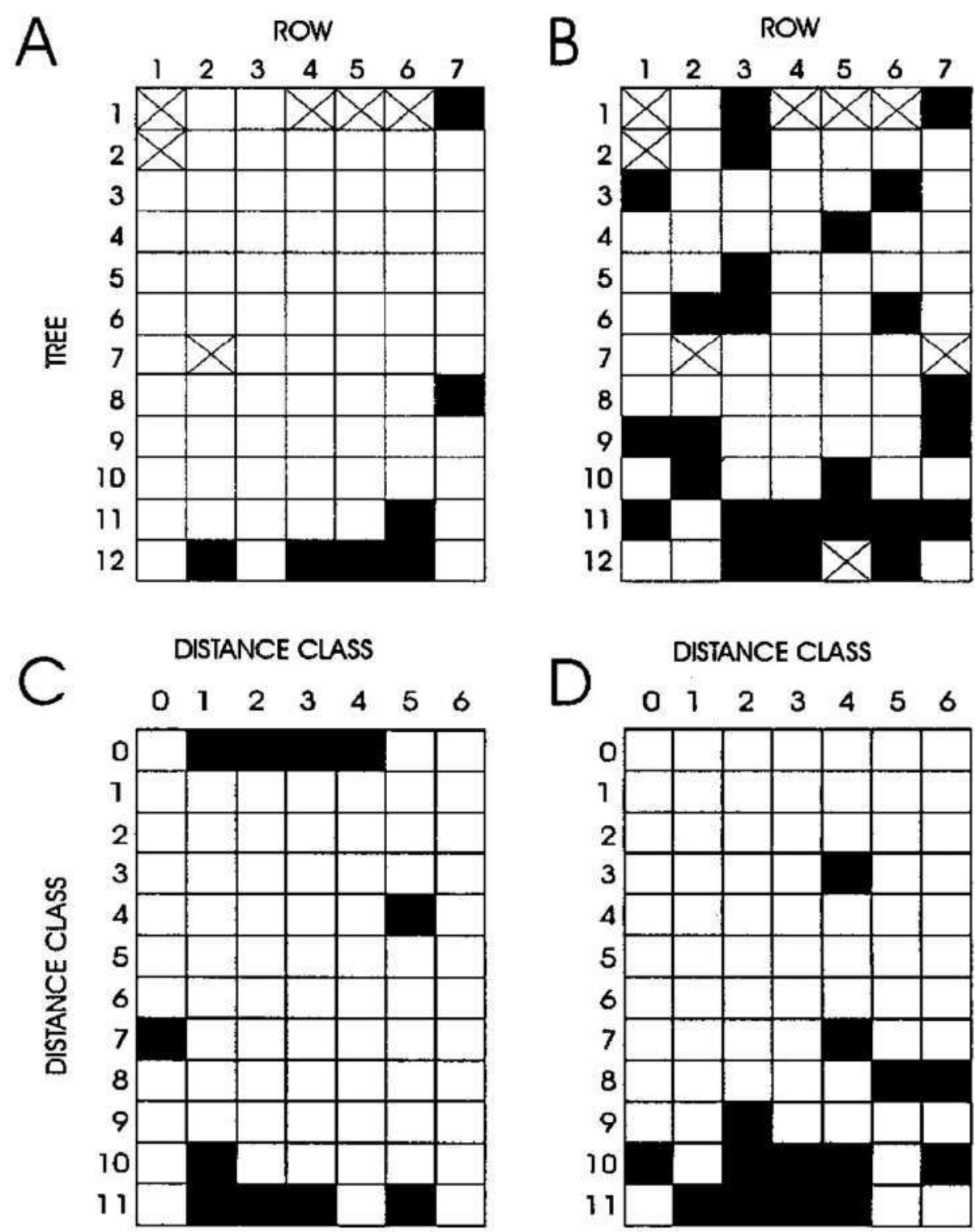

$E$

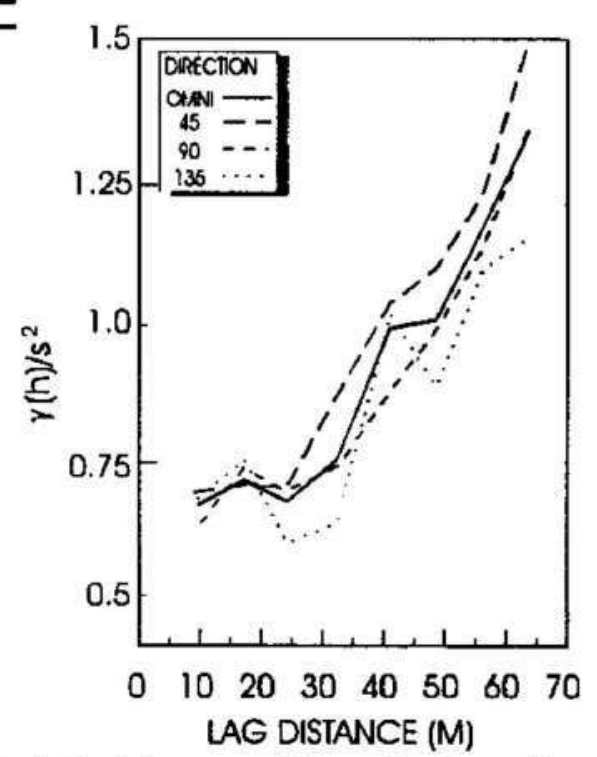

D

DISTANCE CLASS

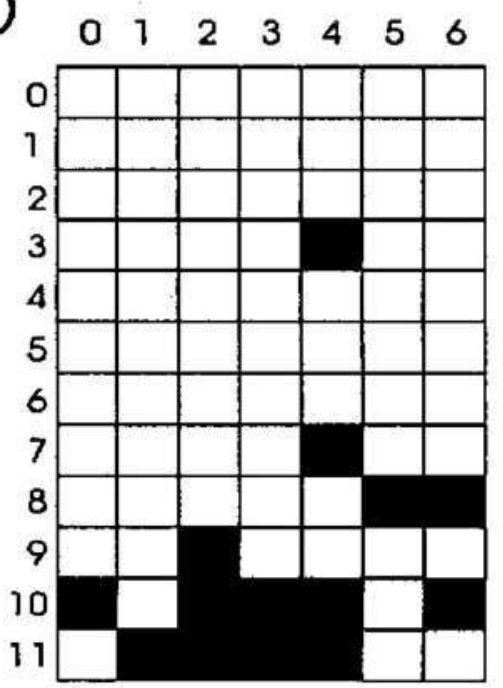

$\mathrm{F}$

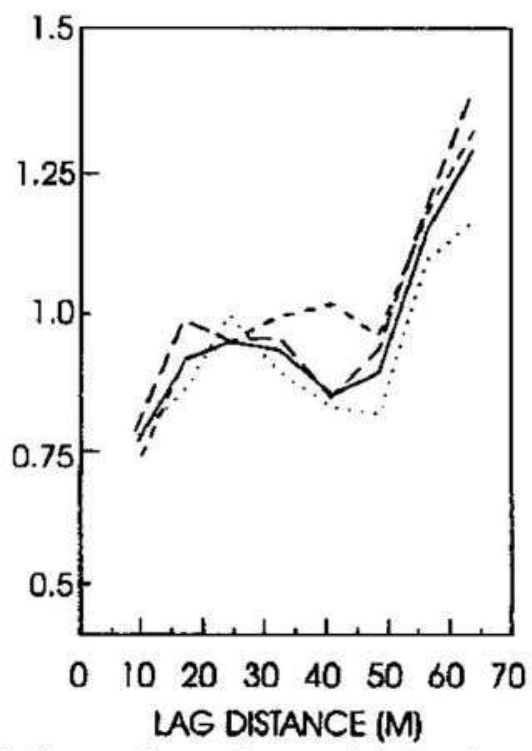

Fig. 3. Spatial pattern with associated two-dimensional distance class and geostatistical analyses by year of sharka disease of a Blanco apricot orchard (plot 3a) in eastern Spain. (A-B) Spatial patterns were determined by double antibody sandwich-enzyme-linked immunosorbent assay using polyclonal antisera for plum pox potyvirus (PPV). Black squares, white squares, and squares with an ' $\mathrm{X}$ ' indicate position of PPV-positive, healthy and missing trees, respectively. (C-D) Proximity pattern matrices from two-dimensional distance class analyses. Black, gray and white squares indicate $[X, Y]$ distance classes with standardized count frequencies greater than expected, less than expected, and as expected, respectively $(P<0.05)$. (E-F) Nonoriented (solid line) and oriented (broken lines) semivariograms of sharka disease spread measured at one-tree intervals. 


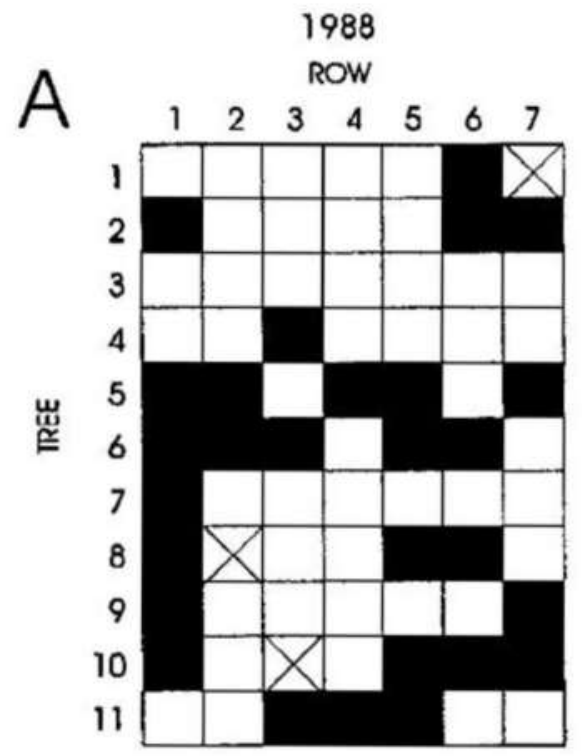

C

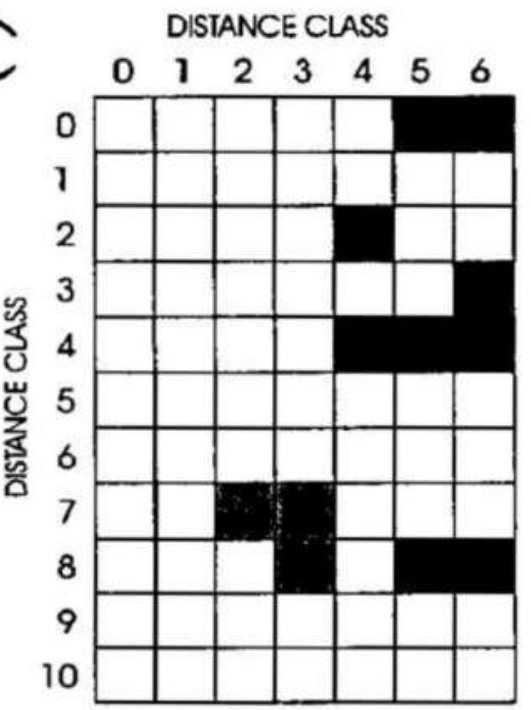

E

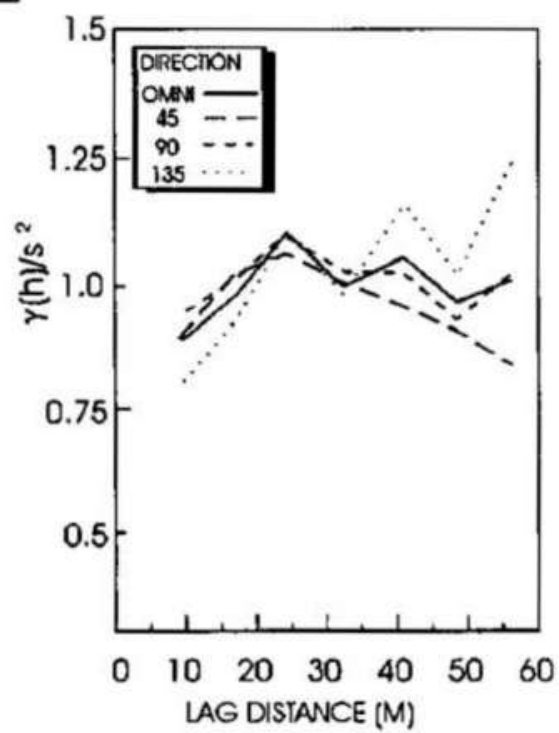

1989

Row

B
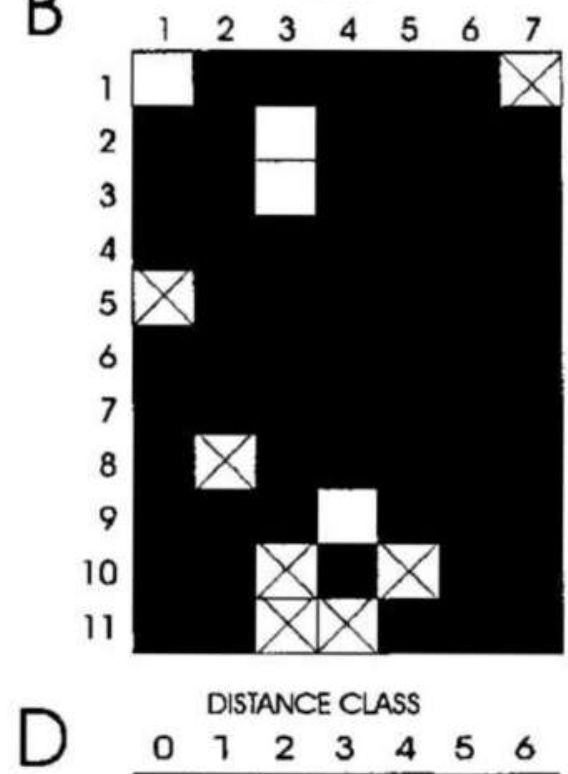

DISTANCE CLASS

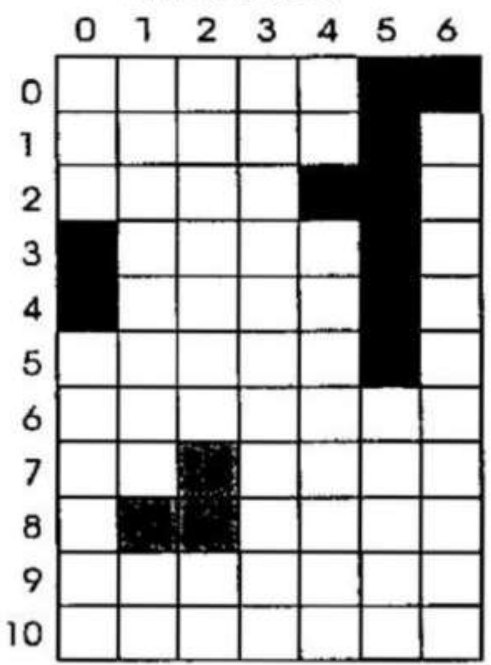

F

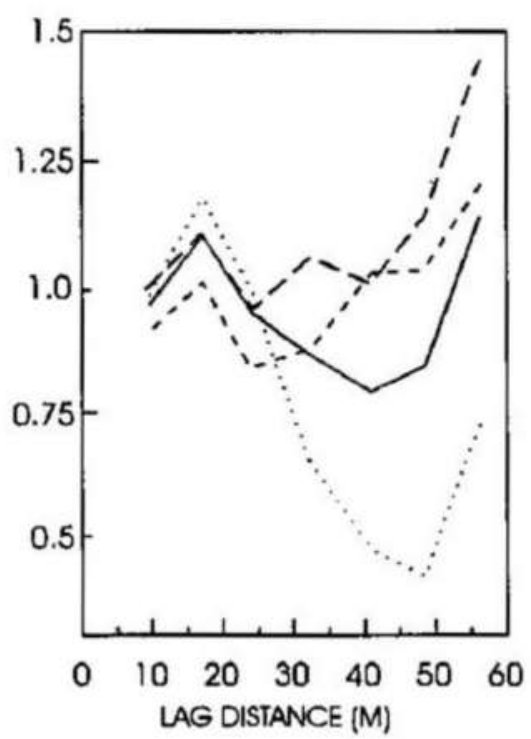

Fig. 4. Spatial pattern with associated two-dimensional distance class and geostatistical analyses by year of sharka disease of a Canino apricot orchard (plot 3b) in eastern Spain. (A-B) Spatial patterns were determined by double antibody sandwich-enzyme-linked immunosorbent assay using polyclonal antisera for plum pox potyvirus (PPV). Black squares, white squares, and squares with an ' $\mathrm{X}$ ' indicate position of PPV-positive, healthy and missing trees, respectively. (C-D) Proximity pattern matrices from two-dimensional distance class analyses. Black, gray and white squares indicate $[X, Y]$ distance classes with standardized count frequencies greater than expected, less than expected, and as expected, respectively $(P<0.05)$. (E-F) Nonoriented (solid line) and oriented (broken lines) semivariograms of sharka disease spread measured at one-tree intervals.

dence is $<0.15$ or $>0.8$, two-dimensional distance class analysis may no longer be appropriate (31). Thus, a nonsignificant, two-dimensional distance class, proximity pattern was determined only for plot 1 for the 1991 assessment, when the total number of expected SCF values was $<5 \%$ and the associated proximity pattern was considered to indicate a random distribution (Table 3). Significantly less than expected SCF values were less common $(<7 \%)$ with the exception of the 1990 assessment of plot 1 (approximately $11 \%$ ). Two-dimensional distance class proximity patterns exhibited few or small core clusters, i.e., significant distance classes immediately adjacent to the origin (distance class $[0,0]$ ) (Figs. 1E,F, 2D,F, and $3 \mathrm{C}$, and Table 3), compared with the number of SCFs encountered at farther distance classes. Significant SCFs were often exhibited at four to seven (Figs. IE-G, 2E,F, 3C,D, 4C,D, and SC,D), and again at nine to 15 (Figs. 1E-G, 2D-F, 3C,D, and 5C,D) distance classes from the origin. The highest densities of distance classes with significantly positive SCFs, composing loose clusters, were often located farther from the origin at distance classes [(4-10), (8-22)] and demonstrated the presence of discontinuous proximity patterns for most of the plots during some point in the early stages of the epidemics (i.e., when disease incidence $<0.5$ ) (Figs. 1F, G, 2F, 3C,D, and 5C,D). Significant edge effects were indicated in eight of the 10 data sets in which aggregation was predicted by the two-dimensional distance class simulation (Table 3 ). The most frequently occurring cluster shape was amorphous; however, row-oriented and column-oriented cluster shapes were also common. The square/rectangular cluster shape was seen only once (Table 3).

Semivariance tended to increase with distance for the majority ( 10 out of 13 ) of the plots and years with the exception of plot 2 during 1990, plot $3 \mathrm{~b}$ for 1988, and plot 4 during 1991 (Figs. 2I, 4E, and $5 F)$. Transitional models assume spatial dependence near the $y$-axis, which decreases to form a sill or plateau at greater spatial distances. This occurred only rarely with the PPV semivariance data. Those transitional models that did fit were characterized by the formation of a sill very close to the $y$-axis, often within the first two lags, and large ranges of spatial dependence often exceeding the dimensions of the plots (Table 4, plot I for 1991, etc.). Thus, although traditional transitional models were capable of fitting the data due to general model plasticity, and accounted for a large portion of the variation in the data due to regression, they did not describe well the spatial structure of semivariance over distance. However, the general trend toward higher semivariance values at the distal end of the semivariogram was well described by simple linear or exponential 

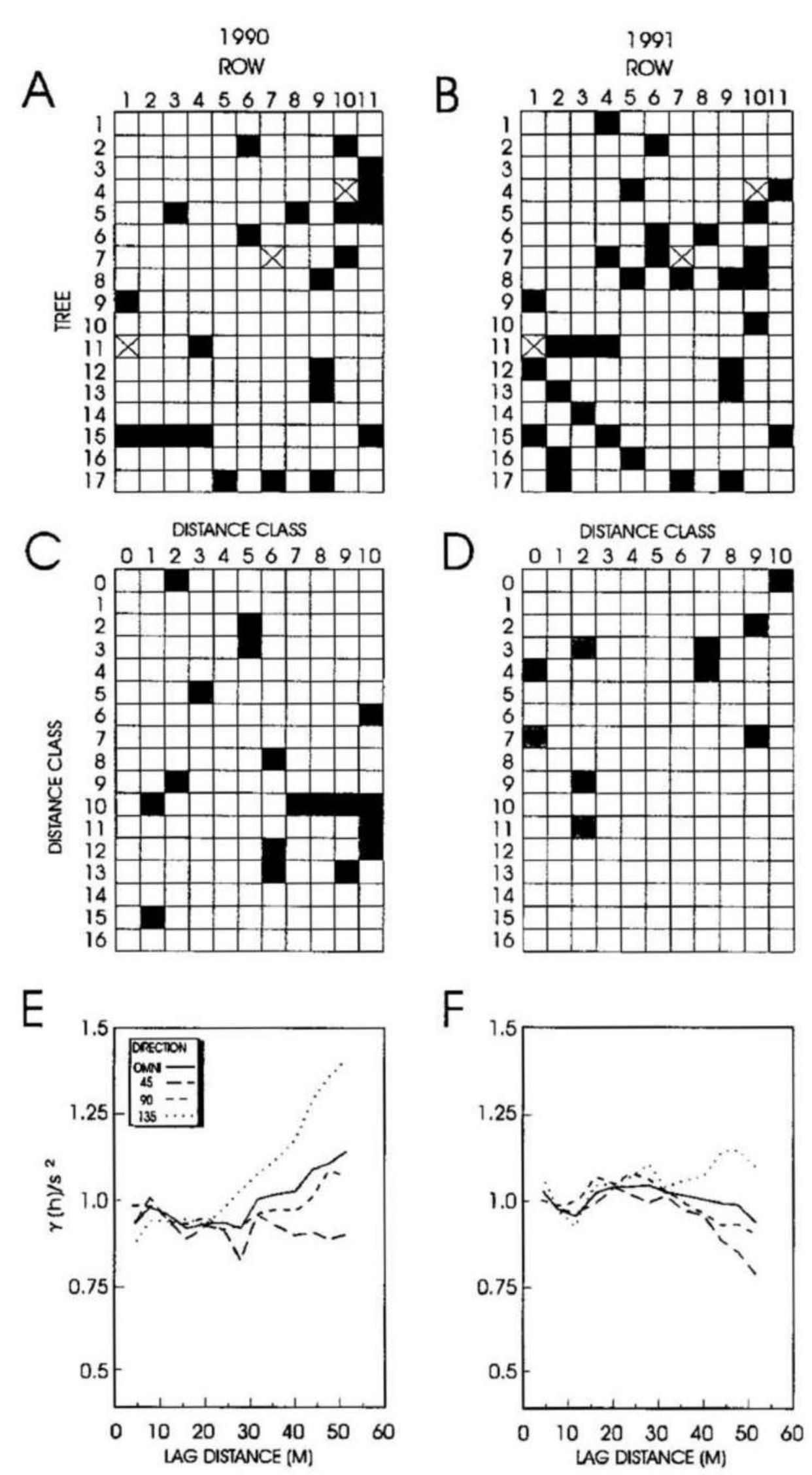

Fig. 5. Spatial pattern with associated two-dimensional distance class and geostatistical analyses by year of sharka disease of a Starcrest peach orchard (plot 4) in eastern Spain. (A-B) Spatial patterns were determined by double antibody sandwich-enzyme-linked immunosorbent assay using polyclonal antisera for plum pox potyvirus (PPV). Black squares, white squares, and squares with an ' $\mathrm{X}$ ' indicate position of PPV-positive, healthy and missing trees, respectively. (C-D) Proximity pattern matrices from two-dimensional distance class analyses. Black, gray and white squares indicate $[X, Y]$ distance classes with standardized count frequencies greater than expected, less than expected, and as expected, respectively $(P<0.05)$. (E-F) Nonoriented (solid line) and oriented (broken lines) semivariograms of sharka disease spread measured at one-tree intervals. models (Table 5). Considering only these two models, the linear and exponential functions were chosen as the more appropriate for $21 / 52$ and $27 / 52$ cases, respectively, with four ties.

These results were consistent with the two-dimensional distance class results that indicated relatively few significant distance classes near the origin and higher densities of positive SCF distance classes further from the origin. Closer examination of plot 1 for 1990 , plot 2 for 1990 , and plot 4 for 1991 revealed an increase in nonoriented semivariance followed by a decrease associated with longer distances (Figs. 1K, 2H, and 5F). This decrease over longer distances for the particular plot-by-year combinations corresponded to concentrations of significantly positive SCF values in the twodimensional distance class matrices corresponding to $[X, Y]$ distance classes separated from the core cluster (Figs. 1G, 2E, and 5D). Plot $3 \mathrm{~b}$ for 1989 had a disease incidence level of 0.95 , and, therefore, squared differences for values between trees separated by a given distance were not detectable. The resulting semivariograms had plateaus or valleys (Fig. 4F).

Some anisotropy was suggested by directional semivariograms, i.e., some directional orientation was indicated for disease distribution for some plot/year combinations. Semivariance was generally higher for $135^{\circ}$ and lower for $45^{\circ}$ directional orientation, respectively, compared with the nondirectional semivariogram for plots $1,2,3 \mathrm{~b}$, and 4 for assessment years when disease incidence was $<0.5$ (Figs. 1I,J, 2G, 4E, and 5E,F). No clearly discernible differences were seen in semivariograms for directional orientation for plot 3 during the early stages of the epidemic (Fig. 2G-I).

The disease incidence of PPV-positive branches was examined by correlation of directional orientation (side of the tree) from one year to the next to determine if the sectoring observed for individual trees was conserved from year to year. All correlations among years for each orientation were highly significant $(P<0.01)$ indicating a conservation of orientation of infection (Table 6). Correlation coefficients were highest between years for orientations with lower changes in disease incidence and lowest between years when there were large changes in disease incidence.

\section{DISCUSSION}

Sharka epidemics in stone-fruit orchards are perennial and require from three to several years to approach an asymptote of disease (13). Often more than one aphid species, i.e., potential vector for PPV, occurs in an orchard at the same time or at different points in time and for different durations during the course of an epidemic (33). The nonpersistent vector efficiency differs among the potential vectoring species of aphid 
as does their population dynamics in response to host and environmental variables $(1,18,22,27,33)$. Thus, even though viruliferous aphid movement is undoubtedly the most important component of the spatial process of sharka epidemics, the number of variables involved in movement of PPV is large and the factors determining the success of transmission of PPV among trees are complex. Examination of spatial analyses and comparison of results at different points in an epidemic may give some clues to PPV movement and distances traversed by viruliferous aphid vectors that were successful in transmission. However, any inference about the time of successful transmission, the aphid species involved, and the efficiency of the aphid population to transmit PPV in relationship to its size and feeding characteristics, is beyond the scope of such analyses.

Ordinary runs analysis indicated only infrequent within- and across-row aggregations of immediately adjacent trees. Significant $\mathbf{I}_{\beta}$ values were generally near one for the majority of quadrat sizes tested, which indicated that aggregation of sharka-diseased trees was infrequent when disease incidence was low. Significant $I_{\beta}$ values were most frequent when disease incidence approached 0.5 and individual diseased trees or clusters coalesced, and thus were not valuable indicators of aggregation. Both ordinary runs and beta-binomial distribution analyses examine the data for aggregation among immediately adjacent diseased individuals or quadrats. Strong indication of adjacency of sharkadiseased trees was clearly absent or inconclusive, which suggested that if spatial associations existed, they would have to be of a higher order, i.e., over longer distances. This conclusion is in direct contrast to previous observations and anecdotal data $(14,30)$.

The lack of clearly definable disease gradients may indicate spatial processes on a scale larger than the size of the individual plots. The orchards examined in this study were of common size for the Valencia area. Two-dimensional distance class analyses confirmed the scarcity of core clusters (significant distance classes near the origin) but did indicate the presence of significant higher order distance classes over larger spatial dimensions at approximately 4-7 and again at 9-15 trees (distance classes) from the origin, and these were generally scattered. Cluster size was generally small involving only $2-4[X, Y]$ distance classes and without clear directional orientation, i.e., within-, across-, or diagonal to rows. This lack of directional orientation indicates no clearly defined directional movement of PPV within plots from tree to tree. Occasionally some amorphous clusters were also determined at $[X, Y]$ distance class coordinates $[(4-10),(8-22)]$ from the origin and may suggest that secondary spread over longer distances, i.e., several trees distant, was common. The presence of edge effects in over half of the plot/year combinations may indicate an influence of exogenous sources of inoculum or simply reflect that the dimension of the plots is approximately the same as the dimension of secondary spread within the plot. Such edge effects were observed in one previous study of PPV in apricot orchards in France (30).

Spatial structures of disease that are devoid of aggregation but have higher order spatial associations are often complex and difficult to interpret compared with aggregated structures and are not prevalent in phytopathological literature. Although 2DCLASS analyses pointed to a lack of aggregation and a predominance of spatial relationships over longer distances, the authors were hesitant to make conclusions based on 2DCLASS results alone without further corroboration. Geostatistical analyses of PPV data sets were used to confirm the complex spatial structures indicated by 2DCLASS analyses and to help interpret the numerous higher order spatial associations among PPV+ trees. Nonoriented semivariograms from geostatistical analyses for several of the plots examined increased as a function of distance from the origin and never achieved a sill or asymptote of spatial dependence. This spatial structure was not well explained by traditional transitional models used in geostatistics, which assume a sill of spatial dependence at higher order spatial lags. Transitional models are based on the assumption of aggregation that degrades over distance, which was not the case for PPV data sets. Lower semivariance values occurring at the mid-range and farthest distances tested may be further evidence that secondary spread occurred over a range of distances approximately equivalent to the dimensions of the plots and was better described by linear or exponential growth models. Although linear and exponential growth models are simpler and more easily explained in epidemiological terms than transitional models, even these models did not fully represent the complexities of semivari-

Table 3. Statistics from two-dimensional distance class analysis for sharka symptoms in stone-fruit orchards in the Valencia province of eastern Spain

\begin{tabular}{|c|c|c|c|c|c|c|c|c|c|c|c|}
\hline \multirow[b]{2}{*}{ Plot } & \multirow[b]{2}{*}{ Year } & \multirow{2}{*}{$\begin{array}{c}\text { Disease } \\
\text { incidence }\end{array}$} & \multicolumn{2}{|c|}{ Significance ${ }^{b}$} & \multirow{2}{*}{$\begin{array}{c}\text { Distance } \\
\text { classes }\end{array}$} & \multirow[b]{2}{*}{ Pattern } & \multirow{2}{*}{$\begin{array}{l}\text { Min. } \\
\text { core } \\
\text { size }^{d}\end{array}$} & \multirow[b]{2}{*}{ Shape ${ }^{t}$} & \multirow{2}{*}{$\begin{array}{c}\text { Ave. } \\
\text { cluster } \\
\text { size and } \\
\text { (range) }\end{array}$} & \multirow{2}{*}{$\begin{array}{c}\text { Total } \\
\text { number } \\
\text { clusters }\end{array}$} & \multirow{2}{*}{$\begin{array}{l}\text { Sig. } \\
\text { edge } \\
\text { effect" }\end{array}$} \\
\hline & & & SCF + & SCF- & & & & & & & \\
\hline \multirow[t]{4}{*}{1} & 1988 & 0.054 & 42 & 0 & 322 & A & 0 & $\mathrm{r}, \mathrm{c}, \mathrm{s}, \mathrm{a}$ & $2.1(2-5)$ & 7 & $6 / 35$ \\
\hline & 1989 & 0.148 & 37 & 5 & 322 & A & 0 & $\mathrm{r}, \mathrm{c}, \mathrm{a}$ & $3.3(2-8)$ & 7 & $14 / 35$ \\
\hline & 1990 & 0.516 & 35 & 13 & 322 & A & 2 & $\mathrm{r}, \mathrm{c}, \mathrm{a}$ & $4.7(2-15)$ & 6 & $0 / 35$ \\
\hline & 1991 & 0.815 & 3 & 3 & 322 & $\mathbf{R}$ & 0 & c & $2(2)$ & 1 & $0 / 35$ \\
\hline \multirow[t]{3}{*}{2} & 1989 & 0.336 & 4 & 3 & 132 & A & 2 & c & $1(1)$ & 1 & $0 / 26$ \\
\hline & 1990 & 0.229 & 8 & 0 & 132 & A & 0 & a & $4(4)$ & 1 & $1 / 26$ \\
\hline & 1991 & 0.504 & 22 & 18 & 132 & A & 2 & $\mathbf{c}, \mathbf{a}$ & $10(2-18)$ & 2 & $6 / 26$ \\
\hline $3 a$ & 1989 & 0.338 & 14 & 0 & 84 & A & 0 & $\mathrm{r}, \mathrm{a}$ & $5(2-8)$ & 2 & $7 / 16$ \\
\hline \multirow[t]{2}{*}{$3 b$} & 1988 & 0.387 & 9 & 3 & 77 & A & 0 & $\mathbf{r}, \mathbf{a}$ & $3.3(2-4)$ & 4 & $5 / 16$ \\
\hline & 1989 & 0.947 & 10 & 3 & 77 & A & 0 & $\mathbf{c}, \mathbf{a}$ & $5(2-8)$ & 1 & $2 / 16$ \\
\hline 4 & 1991 & 0.174 & 7 & 3 & 187 & A & 0 & c & $2(2)$ & 1 & $1 / 26$ \\
\hline
\end{tabular}

Number of plum pox potyvirus-positive trees/total number of trees in the orchard.

${ }^{b}$ Number of $[X, Y]$ distance classes with standardized count frequencies (SCF) significantly greater (SCF+) or less (SCF-) than expected.

'Proximity pattern: $R=$ random (number of significant SCFs $<5 \%$ ); $A=$ aggregated $(5 \% \leq$ number of significant $\mathrm{SCF} \leq \leq 80 \%)$; $U=$ uniform, (number of significant SCFs $>80 \%$.

${ }^{d}$ The number of significant SCF+ distance classes contiguous with the origin that form a discrete group.

'Shape of the cluster(s) of significant SCF+ that occurred in the distance class matrix: $r=$ within row; $c=$ within column (i.e., across row); $\mathrm{s}=$ square or rectangular; and $\mathrm{a}=$ amorphous.

'Average size and range in parentheses of the clusters of SCF+ distance classes within the proximity pattern that are noncontiguous with the origin or core clusters.

"Number of clusters of SCF+ distance classes within the proximity pattern that are noncontiguous with the origin or core clusters.

"Proportion (number of significant SCF+ distance classes/total number of edge distance classes) occurring at the two edges of the proximity pattern farthest from the origin, i.e., the outermost row and column of the distance class matrix. 
ance over distance for PPV data. Had plots of larger dimension been studied, perhaps a range of spatial dependence could have been established. Aphid transmission of PPV in nurseries ranges up to $100-120 \mathrm{~m}$. Unfortunately, because PPV has become endemic in the area, larger orchard sizes of mature, PPV-free trees in the initial stages of an epidemic and suitable for further studies to more accurately determine the distance limits of PPV movement are scarce. Directional spread of disease can sometimes be detected during the initial stages of an epidemic and before increases in disease incidence mask directionally oriented patterns. In some cases, for assessments earlier in the sharka epidemics, the magnitude of directional semivariograms was lower in the $45^{\circ}$ orientation, which suggested possible directionality to the movement of PPV within these orchards diagonally across rows. The $45^{\circ}$ (southwest) orientation is consistent with movement from an inoculum source located on the south- eastern edge of the orchard, for plots 1, $2,3 \mathrm{a}$, and $3 \mathrm{~b}$, and inoculum located on the eastern edge of plot 4. Direction spread of PPV from foci of high incidence has been reported previously (30).

PPV is often locally systemic in main scaffold branches and distributed unevenly in the tree, and thus appears to cause a disease sectoring of the tree (9). When disease increase was moderate, correlation analyses indicated that there was a conservation of directional orientation of disease due to sectoring. Con-

Table 4. Results of nonlinear, transitional model fitting data for semivariance over distance for plum pox potyvirus-positive trees in orchards in the Valencia province of eastern Spain

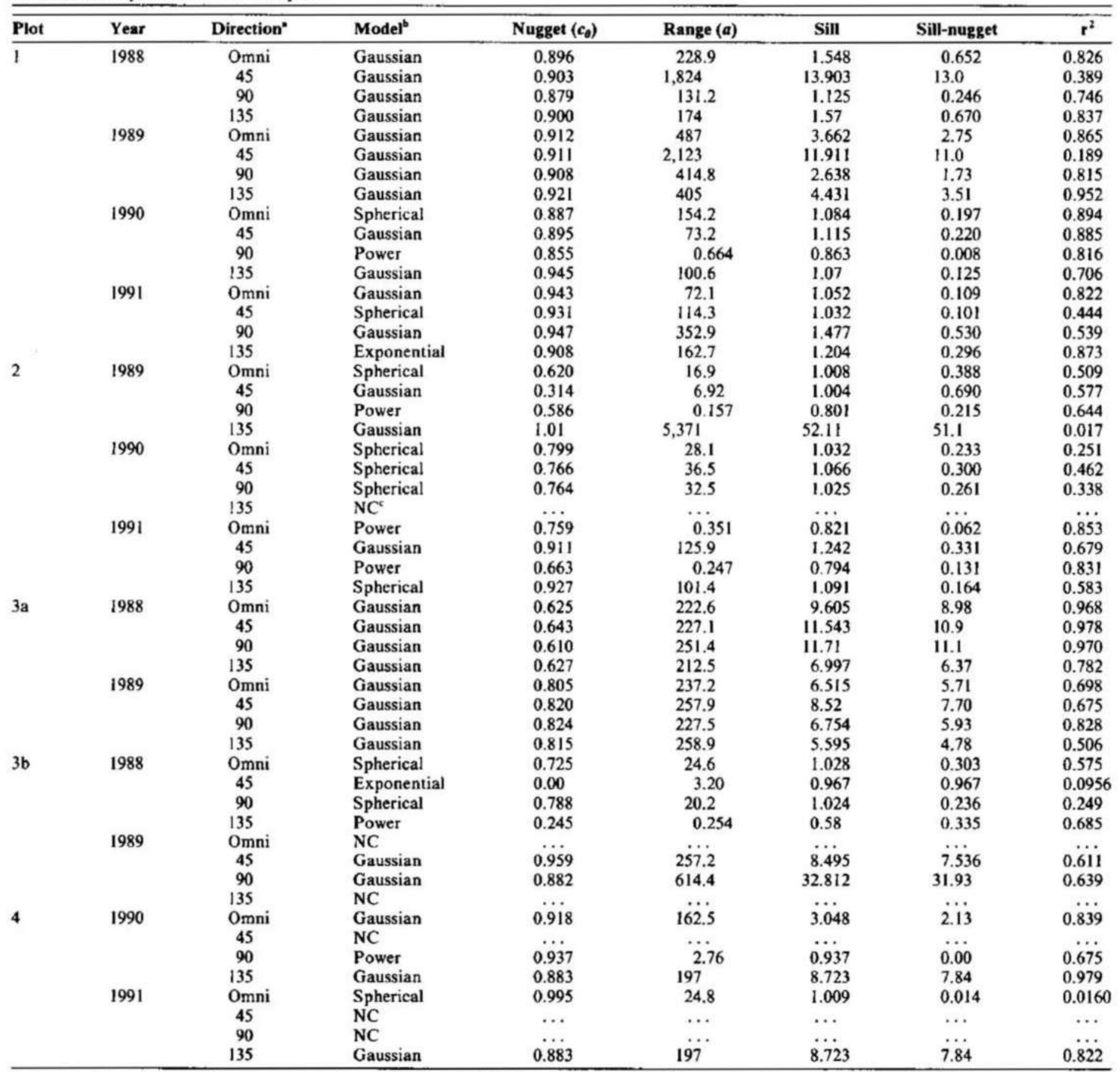

${ }^{2}$ Directional spatial dependence was tested by comparing semivariograms from omnidirectional data sets with directional data sets constructed from those data falling within a $45^{\circ}$ arc along vectors at $45^{\circ}, 90^{\circ}$, and $135^{\circ}$ angle to the horizontal or $x$-axis of the data set.

${ }^{\circ}$ The standardized semivariance $\gamma(h)^{\prime}\left[=\right.$ semivariance/sample variance $\left\{\gamma(h) / \mathrm{s}^{2}\right\}$ vs. lag distance $\left.(m)\right]$ data were fitted by nonlinear regression to $\gamma(h)^{\prime}=c_{0}+\mathrm{B}|h|, \gamma(h)^{\prime}=c_{0}+c_{l}[1-\exp (-3 h / a)], \gamma(h)^{\prime}=c_{0}+c_{l}\left[1-\exp \left(-3 h^{2} / a^{2}\right)\right], \gamma(h)^{\prime}=c_{0}+c_{l}\left[1.5(h / a)-0.5(h / a)^{3}\right]$, and $\gamma(h)^{\prime}$ $=c_{0}+a h^{\mathrm{B}}$ (for $0<\mathbf{B}<2$ ); for the linear, exponential, Gaussian, spherical, and power models, respectively.

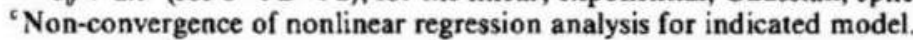


Table 5. Results of linear and exponential model fitting by linear regression of semivariance over distance data for plum pox potyvirus-positive trees in orchards in the Valencia province of eastern Spain

\begin{tabular}{|c|c|c|c|c|c|c|c|}
\hline Plot & Year & Direction" & Model $^{\circ}$ & $\begin{array}{c}\text { Intercept } \\
\left(c_{0}\right)\end{array}$ & $\begin{array}{c}\text { Slope (b) } \\
\text { or }\left(c_{l}\right)\end{array}$ & $r^{2}$ & $r^{* 2}$ \\
\hline \multirow[t]{32}{*}{1} & 1988 & Omni & Linear & 0.8642 & 0.0015 & 0.752 & 0.867 \\
\hline & & 45 & Linear & 0.8951 & 0.0005 & 0.267 & 0.517 \\
\hline & & 90 & Linear & 0.8539 & 0.0013 & 0.663 & 0.814 \\
\hline & & 135 & Linear & 0.8487 & 0.0024 & 0.794 & 0.891 \\
\hline & & Omni & Exponential & -0.1411 & 0.0015 & 0.748 & 0.873 \\
\hline & & 45 & Exponential & -0.1107 & 0.0005 & 0.262 & 0.521 \\
\hline & & 90 & Exponential & -0.1545 & 0.0014 & 0.668 & 0.817 \\
\hline & & 135 & Exponential & -0.1515 & 0.0023 & 0.803 & 0.898 \\
\hline & 1989 & Omni & Linear & 0.8782 & 0.0015 & 0.764 & 0.874 \\
\hline & & 45 & Linear & 0.9088 & 0.0002 & 0.100 & 0.316 \\
\hline & & 90 & Linear & 0.8827 & 0.0012 & 0.659 & 0.812 \\
\hline & & 135 & Linear & 0.8561 & 0.0028 & 0.878 & 0.937 \\
\hline & & Omni & Exponential & -0.1242 & 0.0015 & 0.766 & 0.882 \\
\hline & & 45 & Exponential & -0.0956 & 0.0003 & 0.096 & 0.318 \\
\hline & & 90 & Exponential & -0.1203 & 0.0012 & 0.658 & 0.822 \\
\hline & & 135 & Exponential & -0.1384 & 0.0026 & 0.889 & 0.948 \\
\hline & 1990 & Omni & Linear & 0.9010 & 0.0015 & 0.881 & 0.938 \\
\hline & & 45 & Linear & 0.8801 & 0.0019 & 0.870 & 0.933 \\
\hline & & 90 & Linear & 0.8900 & 0.0014 & 0.817 & 0.904 \\
\hline & & 135 & Linear & 0.9313 & 0.0009 & 0.685 & 0.828 \\
\hline & & Omni & Exponential & -0.1012 & 0.0015 & 0.878 & 0.936 \\
\hline & & 45 & Exponential & -0.1226 & 0.0019 & 0.865 & 0.928 \\
\hline & & 90 & Exponential & -0.1133 & 0.0014 & 0.815 & 0.904 \\
\hline & & 135 & Exponential & -0.0701 & 0.0009 & 0.685 & 0.829 \\
\hline & 1991 & Omni & Linear & 0.9376 & 0.0009 & 0.770 & 0.878 \\
\hline & & 45 & Linear & 0.9520 & 0.0007 & 0.365 & 0.604 \\
\hline & & 90 & Linear & 0.9351 & 0.0005 & 0.490 & 0.700 \\
\hline & & 135 & Linear & 0.9221 & 0.0012 & 0.865 & 0.930 \\
\hline & & Omni & Exponential & -0.0632 & 0.0009 & 0.775 & 0.875 \\
\hline & & 45 & Exponential & -0.0485 & 0.0007 & 0.361 & 0.601 \\
\hline & & 90 & Exponential & -0.0665 & 0.0006 & 0.487 & 0.702 \\
\hline & & 135 & Exponential & -0.0791 & 0.0012 & 0.860 & 0.928 \\
\hline \multirow[t]{25}{*}{2} & 1989 & Omni & Linear & 0.9634 & 0.0006 & 0.363 & 0.602 \\
\hline & & 45 & Linear & 0.9524 & 0.0007 & 0.284 & 0.532 \\
\hline & & 90 & Linear & 0.9106 & 0.0012 & 0.561 & 0.749 \\
\hline & & 135 & Linear & 1.0179 & 0.0001 & 0.002 & 0.044 \\
\hline & & Omni & Exponential & -0.0378 & 0.0006 & 0.362 & 0.601 \\
\hline & & 45 & Exponential & -0.0503 & 0.0007 & 0.286 & 0.529 \\
\hline & & 90 & Exponential & -0.0940 & 0.0013 & 0.559 & 0.744 \\
\hline & & 135 & Exponential & 0.0168 & 0.0001 & 0.002 & 0.044 \\
\hline & 1990 & Omni & Linear & 1.0320 & -0.0002 & 0.011 & 0.103 \\
\hline & & 45 & Linear & 1.0172 & 0.0004 & 0.025 & 0.159 \\
\hline & & 90 & Linear & 0.9966 & 0.0002 & 0.008 & 0.088 \\
\hline & & 135 & Linear & 1.0794 & -0.0013 & 0.235 & 0.485 \\
\hline & & Omni & Exponential & 0.0311 & -0.0002 & 0.013 & 0.100 \\
\hline & & 45 & Exponential & 0.0136 & 0.0004 & 0.025 & 0.155 \\
\hline & & 90 & Exponential & -0.0055 & 0.0002 & 0.007 & 0.085 \\
\hline & & 135 & Exponential & 0.0800 & -0.0014 & 0.265 & 0.476 \\
\hline & 1991 & Omni & Linear & 0.9061 & 0.0017 & 0.828 & 0.910 \\
\hline & & 45 & Linear & 0.8758 & 0.0019 & 0.698 & 0.835 \\
\hline & & 90 & Linear & 0.9086 & 0.0017 & 0.789 & 0.888 \\
\hline & & 135 & Linear & 0.9569 & 0.0014 & 0.530 & 0.728 \\
\hline & & Omni & Exponential & -0.0957 & 0.0017 & 0.821 & 0.907 \\
\hline & & 45 & Exponential & -0.1289 & 0.0019 & 0.688 & 0.836 \\
\hline & & 90 & Exponential & -0.0934 & 0.0017 & 0.783 & 0.884 \\
\hline & & 135 & Exponential & -0.0437 & 0.0014 & 0.521 & 0.724 \\
\hline & & & & & & continue & page) \\
\hline
\end{tabular}

${ }^{2}$ Directional spatial dependence was tested by comparing semivariograms from omnidirectional data sets with directional data sets constructed from those data falling within a $45^{\circ}$ arc along vectors at $45^{\circ}, 90^{\circ}$, and $135^{\circ}$ angle to the horizontal or $x$-axis of the data set.

${ }^{\prime}$ The standardized semivariance $\gamma(h)^{\prime}\left[=\right.$ semivariance/sample variance $\left\{\gamma(h) / s^{2}\right\}$ vs. lag distance $\left.(m)\right]$ data were fitted by linear regression to $\gamma(h)^{\prime}=c_{0}+c_{l}(m)$, and $\gamma(h)^{\prime}=c_{0}+c_{l}[\ln (m)]$; for the linear and exponential models, respectively. $\mathrm{r}^{2}=$ Coefficient of determination for regression analyses. $\mathrm{r}^{* 2}=$ Spearman's correlation coefficient of observed vs. predicted values.

servation of directional orientation of sectoring was somewhat masked when disease incidence rose quickly and eroded the directionality, or when disease incidence was high and the entire tree and all orientations became involved in disease. The presence and conservation of sectoring may indicate that most of the disease increase between assessments for individual trees was due to new infections rather than systemic spread from scaffoid to scaffold.

Sharka disease increase in individual trees appears to be associated with new infections. This, coupled with a general lack of adjacent tree-to-tree spread and a trend toward higher order spatial associations among PPV-positive trees in some orchards, and the presence of some loose clusters at farther distances, begins to elucidate some factors of the possible spatial processes that affect the spread of PPV in Spanish stone-fruit orchards. One explanation for the observed spatial 
Table 5. (continued from preceding page)

\begin{tabular}{|c|c|c|c|c|c|c|c|}
\hline Plot & Year & Direction" & Model $^{b}$ & $\begin{array}{c}\text { Intercept } \\
\left(c_{0}\right)\end{array}$ & $\begin{array}{c}\text { Slope (b) } \\
\text { or }\left(c_{l}\right)\end{array}$ & $r^{2}$ & $r^{* 2}$ \\
\hline \multirow[t]{11}{*}{$3 \mathbf{a}$} & 1988 & Omni & Linear & 0.4536 & 0.0127 & 0.909 & 0.954 \\
\hline & & 45 & Linear & 0.4468 & 0.0147 & 0.924 & 0.961 \\
\hline & & 135 & Linear & 0.4984 & 0.0097 & 0.722 & 0.849 \\
\hline & & Omni & Exponential & -0.6146 & 0.0136 & 0.926 & 0.974 \\
\hline & & 45 & Exponential & -0.5936 & 0.0148 & 0.952 & 0.982 \\
\hline & & 45 & Linear & 0.7260 & 0.0077 & 0.571 & 0.756 \\
\hline & & 90 & Linear & 0.7068 & 0.0083 & 0.814 & 0.902 \\
\hline & & 135 & Linear & 0.7534 & 0.0049 & 0.440 & 0.663 \\
\hline & & Omni & Exponential & -0.2913 & 0.0068 & 0.617 & 0.802 \\
\hline & & 45 & Exponential & -0.2698 & 0.0072 & 0.571 & 0.778 \\
\hline & & 90 & Exponential & -0.3012 & 0.0082 & 0.817 & 0.909 \\
\hline & & Omni & Exponential & -0.0414 & 0.0013 & 0.109 & 0.302 \\
\hline & & 45 & Exponential & 0.0320 & -0.0024 & 0.242 & 0.474 \\
\hline & & 90 & Exponential & 0.0126 & -0.0001 & 0.001 & 0.026 \\
\hline & & 135 & Exponential & -0.1958 & 0.0068 & 0.643 & 0.793 \\
\hline & 1989 & Omni & Linear & 0.9793 & -0.0007 & 0.008 & 0.090 \\
\hline & & 45 & Linear & 0.8926 & 0.0066 & 0.473 & 0.688 \\
\hline & & 90 & Linear & 0.8274 & 0.0051 & 0.505 & 0.711 \\
\hline & & 135 & Linear & 1.2003 & -0.0129 & 0.584 & 0.764 \\
\hline & & Omni & Exponential & -0.0198 & -0.0010 & 0.016 & 0.094 \\
\hline & & 45 & Exponential & -0.0859 & 0.0055 & 0.475 & 0.708 \\
\hline & & 90 & Exponential & -0.1735 & 0.0049 & 0.485 & 0.727 \\
\hline & & 135 & Exponential & 0.2427 & -0.0170 & 0.545 & 0.784 \\
\hline \multirow[t]{7}{*}{4} & 1990 & Omni & Linear & 0.8838 & 0.0040 & 0.695 & 0.834 \\
\hline & & 45 & Linear & 0.9520 & -0.0012 & 0.190 & 0.435 \\
\hline & & 135 & Linear & 0.9797 & 0.0029 & 0.546 & 0.739 \\
\hline & & Omni & Exponential & 0.0224 & -0.0006 & 0.071 & 0.265 \\
\hline & & 45 & Exponential & 0.0659 & -0.0039 & 0.555 & 0.732 \\
\hline & & 90 & Exponential & 0.0646 & -0.0023 & 0.399 & 0.611 \\
\hline & & 135 & Exponential & -0.0198 & 0.0028 & 0.535 & 0.739 \\
\hline
\end{tabular}

Table 6. Correlation of the incidence of sharka symptoms by tree quadrant among years in orchards in the Valencia province of eastern Spain

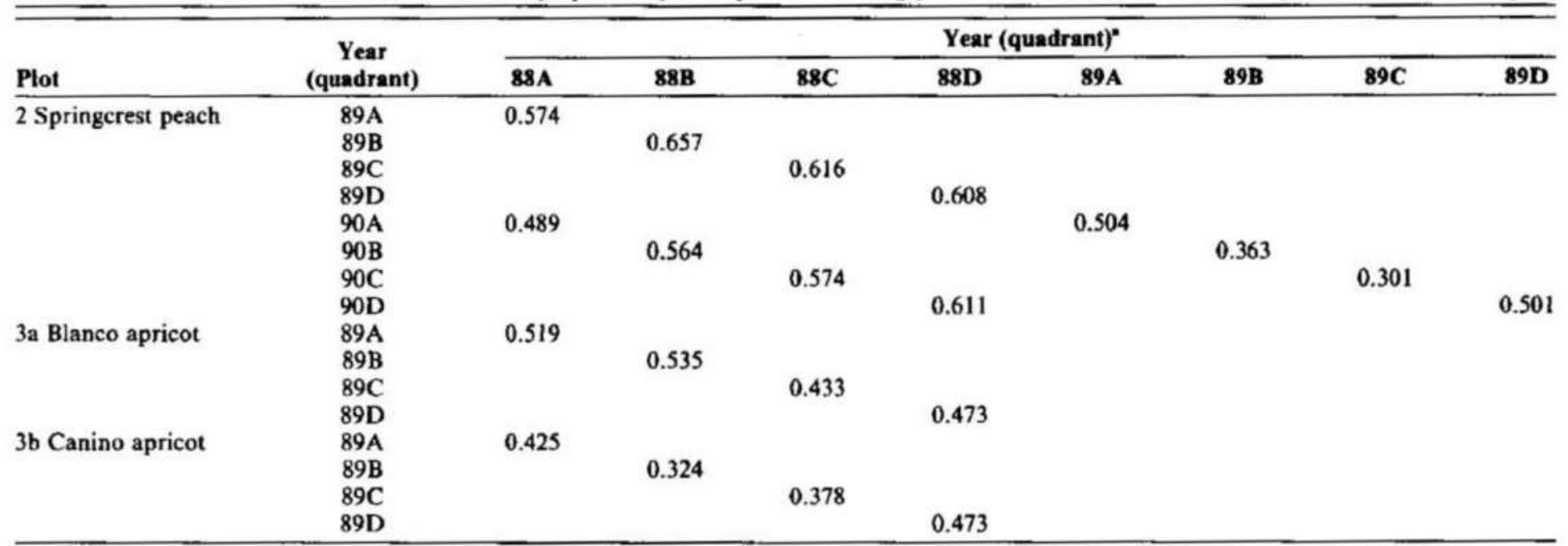

\footnotetext{
"All values were significant at $P \leq 0.003$, for Spearman's coefficient of rank correlation.
} 
proximity patterns of sharka-diseased trees would be that winged, viruliferous aphids, which successfully transmit PPV, preferentially fly several trees away rather than to immediately adjacent trees when foraging for new growth to feed on. This could be due to a more migratory species of aphid such as $A$. gossypii which do not prefer and only infrequently colonize Prunus spp., compared with aphid species that prefer and more frequently colonize Prunus spp. The result would be an apparently more random or uniform distribution of disease as the epidemic progresses but with less obvious higher order associations among diseased trees such as was observed. Alternatively, viruliferous aphids could be moving into the plot from an exogenous source of inoculum in an adjacent infected block. Because the plots were presumed to be PPV-free and remained that way for a number of years after planting, the initial inoculum certainly came from an exogenous source, very probably from the bordering Japanese plum cv. Red Beaut plot, which was $100 \%$ PPV-infected. However, no discernible disease gradients were perceived in any of the data sets and only slight indications of directional orientation for higher order spatial associations were observed. To detect aphid-induced gradients may require plots of spatial size much greater than were available for this study. Lack of perceptible disease gradients also could be due to a low incidence of diffuse initial infections resulting from a few widely scattered viruliferous aphids foraging at some distance from the source of infection. The result would be an apparently random distribution of disease. New waves of aphids originating from a distant, exogenous source of PPV would presumably also be diffuse. However, if this were the case, the apparently random pattern of disease would tend to be maintained with only rare spatial associations over longer distances. This was not the case. Therefore, although some continual influx of exogenous inoculum was very probable, a higher incidence of secondary spread was the more likely dominant spatial process as the epidemics progressed and gave rise to the higher order spatial associations that were detected.

\section{ACKNOWLEDGMENTS}

We wish to express our appreciation to S. Garcia, J. Serra, and P. Bell for technical assistance, and
G. Hughes for assistance with interpretation of betabinomial results.

\section{LITERATURE CITED}

1. Avinent, L., Hermoso de Mendoza, A., and Llàcer, G., 1989. Especies dominantes y curvas de vuelo de pulgones (Homoptera, Aphidinea) en campos de frutales de hueso españoles. Invest. Agrar. Prod. Prot. Veg. 4: 283-298.

2. Avinent, L., Hermoso de Mendoza, A., and Llácer, G. 1993. Comparison of traps for captures of alate aphids (Homoptera, Aphidinea). Agronomic 11:613-618.

3. Avinent, L., Hermoso de Mendoza, A., and Llácer, G. 1993. Comparison of sampling methods to evaluate aphid populations (Homoptera, Aphidinea) alighting on apricot trees. Agronomic. 13:609-613.

4. Cambra, M., and Llácer, G. 1995. Situation of plum pox (sharka) virus in Spain. OEPP/EEPO Bull. (In press.)

5. Cambra, M., Llácer, G., and Pérez de Sanromán, C., 1982. Use of enzyme-linked immunosorbent assay (ELISA) for virus detection on stone fruit trees in Spain. Acta Hortic. 130:145-150.

6. Campbell, C. L., and Madden, L. V. 1990 . Introduction to Plant Disease epidemiology. John Wiley \& Sons, NY.

7. Chellemi, D. O., Rohrbach, K. G., Yost, R. S., and Sonoda, R. M. 1988. Analysis of the spatial pattern of plant pathogens and discased plants using geostatistics. Phytopathology 78:221-226.

8. Conti, M. 1986. Epidemiology and vectors of plum pox virus of stone fruits. Inf. Fitopatol. 36:23-26.

9. Cressic, N. 1985. Fitting variogram models by weighted least squares. Mathematical Geology. 17:563-586.

10. Cressie, N. 1988. Spatial prediction and ordinary kriging. Mathematical Geology. 20:405-421.

11. Dunez, J. and Sutic, D. 1988. Plum Pox virus Pages 44-46 in: European Handbook of Plant Discases. Smith, Dunez Lelliot, Philips, and Archer, eds. Blackwell Scientific Publications, Oxford.

12. Festic, H. 1978. Investigation of new sharka in apricot trees. Acta. Hortic. 74: 233-240.

13. Garcia, S., Martín, M. M., Avinent, L., Llácer, G., Hermoso de Mendoza, A., and Serra, D. 1991. Spread of sharka in apricot trees. Acta Hortic. 298: 563-568.

14. Grzyb, Z. S. 1984. Spread of the plum pox virus in the ltalian plum orchard. Fruit Sci. Rep. 11:155-158.

15. Hermoso de Mendoza, A., Fuertes, C., and Serra, J. 1986. Proporciones relativas y graficas de vueio de pulgones (Homoptera. Aphidinea) en los cítricos españoles. Invest. Agrar. Prod. Prot. Veg. 1(3): 393-408.

16. Hermoso de Mendoza, A. and Moreno, P. 1989. Cambios cuantitativos en la fauna afídica de los citricos valencianos. Bol. San. Veg. Plagas 15: 139-142.

17. Hughes, G., and Madden, L. V. 1993. Using the beta-binomial distribution to describe aggregated patterns of disease incidence. Phytopathology 83:759-763.

18. Kunze, L., and Krezal, H., 1971. Transmission of sharka virus by aphids. Ann. Phytopathol. No. hors série:255-260.

19. Labonne, G., Quiot, J. B., and Hubert, 1. 1988. Les pucerons vecteurs de la sharka dans un verger d'abricotier du sud-est de la France: Premiers résultats. Pages 25-32 in: Agriculture.
L'abricotier. EUR 114229FR. J. M. Audergon, ed. Luxembourg, Commiss. Comm. Europtennes.

20. Leclant, F., 1973. Aspect écologique de la transmission de la Sharka (plum pox) dans le sudest de la France. Ann. Phytopathol. 5:431-439.

21. Lecoust, R., Fargette, D., Fauquet, C., and de Reffye, P. 1989. Analysis and mapping of the spatial spread of African cassava mosaic virus using geostatistics and the kriging technique. Phytopathology 79:913-920.

22. Llácer, G., Avinent, L., and Hermoso de Mendoza, A. 1992. Epidemiology of plum pox (sharka) virus in Valencia (Spain). Acta Hortic. 309: 129-134.

23. Llácer, G. Cambra, M., and Laviña, A 1985. Detection of plum pox virus in Spain. OEPP EPPO Bull. 15:325-329.

24. Llácer, G., Cambra, M., Laviña, A., and Aramburu, J., 1986. Investigations on plum pox (sharka) virus in Spain. Acta Hortic. 193:155-160.

25. Madden, L. V., and Hughes, G. 1994. BBD. Computer software for fitting the beta-binomial distribution to disease incidence data. Plant Disease 78:536-540.

26. Madden, L. V., Louie, R., A bt, J. J., and Knoke, J. K. 1982. Evaluation of tests for randomness of infected plants. Phytopathology 72:195-198.

27. Maison, P., and Massonic, G., 1976. Mthodologie de la transmision en laboratoire de la sharka de pêcher a pêcher par Myzus persicae Sulzer. Bull. Inform. Sharka 2:4-7.

28. Matherson, G. 1963. Principals of geostatistics. Fcon. Geol. 58:1246-1266.

29. Modjeska, J. S., and Rawlings, J. O. 1983. Spatial correlation analysis of uniformity data. Biometrics 39:373-384.

30. Morvan, G. 1989. The epidemiology of plum pox virus in apricot orchards in southern France: description of computer tools and main observations. Acta Hortic. 235:263-270.

31. Nelson, S. C., and Campbell, C. L. 1993. Comparative spatial analysis of foliar epidemics on white clover caused by viruses, fungi, and a bacterium. Phytopathology 83:288-301.

32. Nelson, S. C., Marsh, P. L., and Campoell, C L. 1992, 2DCLASS, a two-dimensional distance class analysis software for the personal computer. Plant Dis. 76:427-432.

33. Nemeth, M., and Kõlber, M. 1988. Plum pox (sharka) virus infection of apricot cultivars. Acta Hortic. 209:155-162.

34. OEPP/EPPO. 1974. Progrès realisés dans Ia connaissance de la sharka. OEPP/EPPO Bull. 4:1-126.

35. OEPP/EPPO. 1983. Data sheets on quarantine organisms No. 96. Plum pox virus. OEPP/ EPPO Bull. 13:1-7.

36. Schotzko, D. J., and O'Keeffe, L. E. 1989. Geostatistical description of the spatial distribution of Lygus hesperus (Heteroptera: Miridac) in lentils. J. Econ. Entomol. 82:1277-1288.

37. Smith, I. M., McNamera, D. G., Scott, P. R., and Harris, K. M. (Eds.) 1992. Plum pox potyvirus. Pages $922-927$ in: CABI/EPPO. Quarantine Pests for Europe.

38. Tangmar, B. B., Yost, R. S., and Uehara, G. 1985. Application of geostatistics to spatial studies of soil properties. Adv. Agron. 38:45-94.

39. Upton, G., and Fingleton, B.. 1984. Spatial Data Analysis by Example. John Wiley and Sons. Chichester, England

40. Vieira, S. R., Hatfield, J. L., Nielson, D. R., and Bagger, J. W. 1983. Geostatistical theory and application to variability of some agronomical properties. Hilgardia 51:1-75. 